NBER WORKING PAPER SERIES

AGE, SOCIOECONOMIC STATUS AND OBESITY GROWTH

Charles L. Baum II

Christopher J. Ruhm

Working Paper 13289

http://www.nber.org/papers/w13289

\author{
NATIONAL BUREAU OF ECONOMIC RESEARCH \\ 1050 Massachusetts Avenue \\ Cambridge, MA 02138 \\ August 2007
}

We thank seminar participants at the National Bureau of Economic Research and Triangle Health Economics Workshop for useful comments, as well as Darius Lakdawalla for help obtaining measures of job-related physical demands. The views expressed herein are those of the author(s) and do not necessarily reflect the views of the National Bureau of Economic Research.

(C) 2007 by Charles L. Baum II and Christopher J. Ruhm. All rights reserved. Short sections of text, not to exceed two paragraphs, may be quoted without explicit permission provided that full credit, including $\odot$ notice, is given to the source. 
Age, Socioeconomic Status and Obesity Growth

Charles L. Baum II and Christopher J. Ruhm

NBER Working Paper No. 13289

August 2007

JEL No. I12

\begin{abstract}
$\underline{\text { ABSTRACT }}$
The rapid growth in obesity represents a major public concern. Although body weight tends to increase with age, the evolution of obesity over the lifecycle is not well understood. We use longitudinal data from the National Longitudinal Survey of Youth to examine how body weight changes with age for a cohort moving through early adulthood. We further investigate how the age-obesity gradient differs with socioeconomic status (SES) and begin to examine channels for these SES disparities. Our analysis uncovers three main findings. First, weight rises with age but is inversely related to SES at given ages. Second, the SES-obesity gradient widens over the lifecycle, a result consistent with research examining other health outcomes such as overall status or specific medical conditions. Third, a substantial portion of the SES "effect" is transmitted through race/ethnicity and the translation of advantaged family backgrounds during childhood into high levels of subsequent education. Conversely, little of the SES difference appears to be propagated through family income, marital status, number of children, or the set of health behaviors we control for. However, approximately half of the SES-weight correlation persists after the inclusion of controls, illustrating the need for further study of mechanisms for the gradient.
\end{abstract}

Charles L. Baum II

Economics and Finance Department

P. O. Box 27

Middle Tennessee State University

Murfreesboro, TN 37132

cbaum@mtsu.edu

Christopher J. Ruhm

Department of Economics

Bryan School, UNCG

P.O. Box 26165

Greensboro, NC 27402-6165

and NBER

chrisruhm@uncg.edu 


\section{Age, Socioeconomic Status and Obesity Growth}

Although a positive relationship between socioeconomic status (SES) and health has been widely documented (Marmot et al., 1991; Smith, 2004), sources of these disparities are not well understood. Medical researchers and epidemiologists tend to emphasize the causal effects of SES, whereas economists frequently focus on how health influences SES or the role of additional factors (such as discount rates or genetics) that may be correlated with both. In an effort to identify the causal impact of SES, some analysts have recently focused on health disparities early in life and on the evolution of these gradients as age increases. A primary advantage of this approach is that health status is unlikely to significantly affect the SES of youths, since the latter is largely determined by the economic situation of the child's parents. Most such investigations suggest that SES-health gradients become more pronounced with age, through at least early adulthood.

The current analysis contributes to this line of study by examining how body weight and obesity evolve during the transition from early through the middle adult years. The focus on weight is useful for several reasons. First, obesity is an important risk factor for premature death (Allison et al., 1999; Fontaine et al., 2003; Flegal et al., 2005) and health problems like diabetes, gallbladder disease, coronary heart disease, high cholesterol, hypertension and asthma (Must et al., 1999; Mokdad et al., 2001; McTigue et al., 2006). Excess weight reduces the quality of life, raises medical expenditures, places stress on the health care system and results in productivity losses due to disability, illness and premature mortality (Quesenberry et al., 1998; Finkelstein et al., 2003; Andreyeva et al., 2004). A second advantage is that changes in body weight are easily observable, 
whereas many health indicators (such as overall health status or specific medical conditions) are likely to be measured with greater error or require interaction with the medical system for diagnosis. ${ }^{1}$ Third, obesity represents a rapidly increasing health risk. Using conventional definitions, 31 percent of 18-74 year olds were obese in 1999-2004, compared to just 14 percent in 1976-1980 (Ruhm, 2007). Fourth, obesity generally develops over a lengthy period of time - since body weight is a stock resulting from flows of caloric intake and expenditures - and so may reflect an accumulation of the effects of SES differences. Consistent with this, excess weight during childhood, particularly in late adolescence, is a strong predictor of adult obesity (Whitaker et al., 1997; Guo et al., 2002; McTigue et al., 2002).

We use longitudinal data from the National Longitudinal Survey of Youth (NLSY) to investigate: body weight changes with age for a cohort moving through early adulthood; SES differences in this age-obesity gradient; and channels for the SES disparities. Our analysis shows that weight increases with age and is inversely related to SES. The obesity gradient widens over the lifecycle, consistent with research examining other health outcomes such as overall status or specific medical conditions. A substantial portion of the SES "effect" operates through race/ethnicity and the translation of advantaged family backgrounds during childhood into higher levels of subsequent education. By contrast, little of the SES gap appears to propagate through household composition, family incomes or the health behaviors we account for. However, approximately half the SES-weight correlation persists after the inclusion of controls, highlighting the need for further study of mechanisms for the gradient.

\footnotetext{
${ }^{1}$ Chang and Christakis (2005) give similar reasons for using body weight/obesity outcomes to examine the relationship between income inequality and health.
} 


\section{Socioeconomic Status and Obesity}

Adult body weight and obesity are inversely related to social and economic advantage. Previous research, for instance, indicates that the prevalence of obesity declines with income and education, and is more common for minorities than whites. Thus, 31 percent of non-Hispanic whites aged 20 and older were obese in 2003-2004, using clinical measures of height and weight, compared to 37 percent of Hispanics and 45 percent of non-Hispanic blacks (Ogden et al., 2006). Using self-reported data (which results in lower prevalence estimates than clinical measures), 26 percent of high school dropouts were obese in 2000, versus 22 percent of high school completers and 15 percent of college graduates (Mokdad et al., 2001). Similarly, 23 (14) percent of white women (men) with family incomes greater than 400 percent of the poverty line were obese in 1999-2002, compared to 40 (34) percent of their poor counterparts, although this distinction is not always present for nonwhites (Chang and Lauderdale, 2005).

These patterns are consistent with evidence that high SES adults are healthier than their less advantaged peers. Pathways, however, are difficult to identify. SES certainly may have causal effects on body weight. For example, Drewnowski and Specter (2004) attribute some of the high obesity rates of disadvantaged groups to the relatively low cost of energy-dense foods, since poor individuals can more easily cover caloric requirements by purchasing high-calorie products. Similarly, the "weathering" hypothesis (Geronomius et al., 2006) emphasizes the cumulative impact of social or economic adversity and political marginalization. On the other hand, economists show that obese individuals receive a wage penalty (Averett and Korenman, 1996; Baum and Ford, 2004; Cawley, 2004), suggesting that excess weight reduces income-based measures of SES. 
Finally, unobserved factors could determine both SES and body weight. For instance, high discount rates may simultaneously reduce educational investments and decrease the willingness to forgo current caloric intake for the future benefit of lower weight (Fuchs, 2004; Smith et al., 2005; Borghans and Golsteyn, 2006). Self-control problems may also be more common among low SES individuals (Cutler et al., 2003). ${ }^{2}$

Some investigators have focused on SES-health gradients among youths as a promising method of identifying causal effects of SES on health. Examining the young has two advantages. First, it seems unlikely that health could significantly affect SES, since the latter is largely determined by the education and economic circumstances of the parents. ${ }^{3}$ Second, although omitted factors transmitted across generations (such as genetics) could play a role, the influence of other potential confounders (like discount rates) would not be expected to affect SES until later in life.

Of particular relevance is research by Case et al. (2002) indicating that the SEShealth gradient "rotates" (steepens) as individuals move from infancy through late adolescence. In subsequent work, Case et al. (2005) show that poor health during childhood is associated with lower educational attainment, lower social status and more health problems in adulthood, suggesting that health is an important mechanism through which economic status is transmitted. ${ }^{4}$ We do not fully understand why the SES gradient rotates. Janet Currie and her coauthors indicate that it is primarily because disadvantaged

\footnotetext{
${ }^{2}$ Sophisticated approaches have been used in an attempt to identify the direction of causality. For instance, Adams et al. (2003) employ procedures similar to (but more advanced than) Granger-causality methods to test for the absence of direct causal paths from SES to innovations in health and from health status to innovations in SES, using data on U.S. senior citizens.

${ }^{3}$ Some effect could remain when proxying socioeconomic status by household income if, for example, parents reduce work when their children have serious health problems (Powers, 2003; Noonan et al. 2005). This is less of an issue for the education-based SES measures on which we focus.

${ }^{4}$ Smith (2004) confirms that health-SES disparities increase through at least age 50 but suggests that a narrowing occurs later in life.
} 
individuals are subjected to a greater number of deleterious health events, rather than being more adversely affected by given shocks (Currie and Hyson, 2002; Currie and Stabile, 2003). Case et al. (2002) suggest, but do not provide conclusive evidence of, a key role for differences in health behaviors.

Body weight and obesity are particularly useful outcomes for understanding agerelated changes in SES-health disparities but have not been directly examined in this context. The most closely related investigation we are aware of is by McTigue et al. (2002). They use data from the 1981 through 1998 years of the National Longitudinal Study of Youth (NLSY) - the same source we analyze use but for a shorter period - to study race/ethnicity differences in the evolution of body weight. Their investigation contained a number of limitations that our analysis attempts to rectify. ${ }^{5}$

\section{Data and Analytical Methods}

Data are from the 1979 cohort of the NLSY, which initially included 12,686 persons aged 14 to 21 in 1979, with oversamples of blacks, Hispanics, low-income whites and military personnel. Annual surveys were conducted through 1994, with biennial interviews since that time. The military sample was dropped in 1984 and the low-income white sample in 1990; therefore we exclude both from our analysis. We also omit females pregnant at the interview date or who have given birth in the last year. ${ }^{6}$ Much of the analysis is performed separately for men and women, reflecting potential differences in lifecycle patterns of body weight and SES effects.

\footnotetext{
${ }^{5}$ McTigue et al., (2002) did not explicitly examine the role of SES or identify sources of observed differences. Also, an extremely limited set of covariates was controlled for and the effects of aging and secular trends in body weight were confounded.

${ }^{6}$ This drops 4,827 person-year observations including a maximum (minimum) of 504 (27) females in 1985 (2004).
} 
The NLSY collects data on individual and family background characteristics during each interview year, with additional retrospective information available from the baseline (1979) survey. Questions about body weight were included in 1981, 1982, 1985, 1986, 1988, 1989, 1990, 1992, 1993, 1994, 1996, 1998, 2000, 2002 and 2004; those on height were incorporated in 1981, 1982 and 1985 (Center for Human Resource Research, 2004). ${ }^{7}$ Our analysis assumes that height does not change after 1985 , since all NLSY respondents were at least 20 years old at that time. Using these data, we calculate the respondent's Body Mass Index (BMI), defined as weight in kilograms divided by height in meters squared. ${ }^{8}$ BMI is less accurate than laboratory measures of body composition because it does not account for variations in muscle mass or in the distribution of body fat (e.g. intra-abdominal versus overall adiposity). Nevertheless, BMI is a favored method of assessing excess weight because it is simple, rapid, and inexpensive to calculate. ${ }^{9}$

Federal and international guidelines define adults with a BMI below 18.5 as "underweight" while those with BMIs in the ranges of 18.5 to $<25,25$ to $<30$ and $\geq 30$ are "normal weight," "overweight" and "obese" (World Health Organization, 1997; National Heart, Lung, and Blood Institute, 1998). ${ }^{10}$ Obesity is further divided into three categories: class 1 (BMI 30 to $<35$ ), class 2 (BMI 35 to $<40$ ) and class 3 (BMI $\geq 40$ ). Our analysis focuses on BMI, obesity and, for some descriptive analysis, class 3 obesity. There are at least two issues with our use of these BMI standards. First, official statistics use a more complicated criterion for children (under the age of 21), based on

\footnotetext{
${ }^{7}$ The questions are "How much do you weigh" and "How tall are you"? Weight is reported in pounds and height in inches.

${ }^{8}$ Equivalently, BMI is weight in pounds divided by height in inches squared times 703.

${ }^{9}$ Some researchers prefer other anthropometric measures such as waist circumference (Sönmez et al., 2003), waist-hip ratio (Dalton et al., 2003), or waist-height ratio (Cox and Whichelow, 1996). Cawley and Burkhauser (forthcoming) have recently recommended the use of Bioelectrical Impedance Analysis (BIA). None of these are available in the NLSY.

${ }^{10}$ The WHO terms those with BMI of 25.0 to $<30$ as "preobese."
} 
gender and age-specific growth charts compiled by the Center for Disease Control and Prevention's National Center for Health Statistics (Kuczmarski et al., 2000). ${ }^{11}$ We use the adult obesity standard $(\mathrm{BMI} \geq 30)$ for all respondents, including those below 21 years old at the interview date, to provide consistency across individuals and over time. However, preliminary analysis confirmed that our results were robust to use of the CDC measure of overweight for respondents under the age of 21.

Second, self-reported data on height and weight is measured with error. Specifically, there is a tendency for height to be over-reported and weight to be understated (Strauss, 1999; Goodman et al., 2000; Kuczmarski et al., 2001), leading to an underestimate of BMI. ${ }^{12}$ A number of (not entirely satisfactory) regression-based procedures have been proposed for correcting the self-report errors (Bolton-Smith et al. 2000; Spencer et al., 2002, Plankey et al., 1997). In the economics literature, researchers (Cawley, 2004; Chou et al., 2004; Ruhm, 2005) have used variations of the following method: 1) regress clinical measures of weight (height) on a quadratic of the corresponding self-reported variable, using data from the third National Health and Nutrition Examination Survey (NHANES 3); 2) use the resulting prediction equation to estimate actual weight and height as a function of self-reported values in a target data set (such as the NLSY) containing only the latter; and 3) calculate BMI using the corrected values for weight and height. ${ }^{13}$ We explored the implications of using this procedure but found that our results were not substantively altered by doing so. Therefore, most

\footnotetext{
${ }^{11}$ Specifically, youths are classified as "overweight" if their BMI is at or above the gender and age-specific $95^{\text {th }}$ percentile and "at risk of overweight" if BMI is between the $85^{\text {th }}$ and $95^{\text {th }}$ percentile. See www.cdc.gov/nccdphp/dnpa/bmi/bmi-for-age.htm for further information.

${ }^{12}$ The magnitude of the underestimate appears to increase with BMI.

${ }^{13}$ Reporting errors are typically allowed to differ across gender and race/ethnicity groups by estimating separate equations or including interaction terms in the first-stage regression.
} 
findings below are based on the (uncorrected) self-report data, although we briefly discuss estimates using corrected BMI.

To maintain a consistent sample across all survey years, we eliminated persons failing to provide valid information on body weight for any of the 15 interview years in which it was collected. Otherwise, changes in sample averages might reflect non-random attrition (e.g. higher exit rates among low-income individuals who also tend to weigh more). ${ }^{14}$ However, as mentioned, we made the exception of excluding women in years they were pregnant or had recently given birth but including them in other periods.

Our primary proxy for SES is the highest grade completed by the respondent's mother, measured at the 1979 interview date. We focus on the maternal education because previous research suggests that it is more directly related to child health than schooling of fathers (Currie et al. 2007), education data are more often missing for fathers, and because mothers may be more instrumental in establishing the eating habits and health behaviors of children. We frequently divide the sample into "low" "medium" and "high" SES groups, defined according to whether the mother has fewer than 12, exactly 12 , or greater than 12 years of completed schooling. Approximately 29, 49 and 22 percent of the NLSY cohort fall into these categories. ${ }^{15}$

The NLSY does not collect the data required to create a measure of SES based on permanent income during the respondent's childhood. However, previous research (Zhang and Wang, 2004; Classen and Hokayem, 2005) indicates substantial health

\footnotetext{
14 To determine the implications of this exclusion restriction, we examined (unweighted) average BMI for each survey year that collected weight information using our balanced sample first and then with an unbalanced sample that included observations for respondents with missing information on BMI in one or more years. Despite substantial differences in sample size, average BMI was similar across the two samples for each year, although always slightly higher in the unbalanced sample. See Appendix Table A.1 for details.

${ }^{15}$ Since the NLSY oversamples minorities, 40, 42 and 17 percent of the unweighted sample were classified as low, medium and high SES using this criterion.
} 
gradients when proxying SES with schooling, suggesting the usefulness of our educationbased measure. As alternatives, we experiment with SES indicators based on: (i) respondent scores on the Armed Forces Qualification Test (AFQT), which is an indicator of cognitive skill measured in $1981^{16}$; (ii) family structure during childhood, classified by the presence or absence of the father in the household when the respondent was 14 years old; (iii) the highest grade completed by the respondent's mother or father; and (iv) the highest Duncan Socioeconomic Index (SEI) occupation score of the respondent's mother or father for the longest job held in $1978 .{ }^{17}$ We do not consider the AFQT and family structure-based measures of SES to be as informative as those based on maternal education, and so comment only briefly on the results obtained when using them.

Additional explanatory variables are incorporated in some specifications. These include: highest grade completed, family income, race/ethnicity, marital status, number of biological children and health behaviors. Except where noted, this information pertains to the respondent in the interview year in which body weight was measured. Family income refers to all sources during the previous calendar year and is expressed in constant (2004 year) dollars, adjusting for price changes using the all-items Consumer Price Index. Marital status is a dummy variable indicating that the respondent was married at the survey date, rather than being separated, divorced, widowed or never married.

We use two strategies to avoid losing observations due to missing values of variables other than BMI. First, for several covariates (age, respondent education, family income and

\footnotetext{
${ }^{16}$ The AFQT variable used is the residual from a regression of AFQT scores on age dummy variables.

${ }^{17}$ The Duncan Socioeconomic Index (SEI) occupation score is based on 1970 U.S. Census occupational classification codes. Duncan SEI scores (Duncan, 1961) have been widely used in the literature to proxy for occupational prestige (see Featherman, Sobel, and Dickens, 1975, and Stevens and Featherman, 1981). Higher SEI scores indicate greater prestige. Respondents were excluded from this portion of the analysis if neither parent worked or was alive in 1978.
} 
married), we replace missing values with values averaged from adjacent survey years containing this information. For instance, if data on family income are missing in 1985 but present in 1984 and 1986, we replace the missing 1985 value with the average of income in 1984 and 1986. Second, we set values of regressors still missing (after using the first procedure) to zero and include a dummy variable denoting the presence of a missing value.

Our controls for health behaviors are limited, both with regard to the information available and years in which it was collected. For instance, we have data on alcohol consumption, cigarette smoking, exercise, and job-related physical demands but none on diet or caloric intake. Our strategy for alcohol and cigarette consumption is to use information from the most recent previous survey in which the relevant questions were asked or from the first survey the data were collected, when this occurred subsequent to the relevant interview date. For instance, if questions were included in 1984, 1992, 1994 and 1998, we use information from 1984 for all survey waves before 1992, 1992 data for 1992 and 1993, the 1994 questions for 1994 through 1996, and 1998 responses for all remaining interviews. ${ }^{18}$ Detailed questions on exercise are limited to 2002 and 2004. Therefore, we averaged values for these two years and applied the results to all periods analyzed. ${ }^{19}$ This procedure relies on the assumption that exercise is highly correlated over time, in which case data from later survey years provides useful information on physical activity earlier in life.

Using drinking questions included in 1983, 1984, 1988, 1989, 1994 and 2002, we constructed dummy variables indicating binge consumption (6 or more drinks in a single session) and heavy drinking (consumption of more than 60 alcoholic beverages) during the

\footnotetext{
${ }^{18}$ To reduce the number of missing values, we used values for one of the nearest adjacent survey years if these contained valid responses but information was not provided in the specified year.

${ }^{19}$ The physical activity variables are constructed using information from 2002 (2004) only if the corresponding data are missing in 2004 (2002). Information on physical activity is also available for 1998 and 2000 but it is much less detailed and so is not used in this analysis.
} 
previous month. ${ }^{20}$ Information on smoking, available in 1984, 1992, 1994 and 1998 was used to create three dummy variables. The first indicates whether the respondent had smoked 100 or more cigarettes during his or her lifetime. The second and third denote current and heavy smoking, with the latter defined as consumption of $\geq 20$ cigarettes per day.

Information on the frequency and duration of "light/moderate" and "vigorous" physical activity and the frequency of strengthening exercises is available in 2002 and $2004 .^{21}$ Four variables are created using averages over these two years,. Individuals are defined as "physically inactive" if they engaged in less than one hour of exercise per week, "moderately active" if they exercised one to two hours weekly, "physically active" if exercising at least two hours per week but less than two hours vigorously, and as "vigorous exercisers" if they engage in more than two hours per week of vigorous physical activities. The final variable indicates participation in strengthening exercises at least once per week. We also incorporate measures of job-related fitness and strength requirements, using data for 1970 U.S. Census occupational classification codes from the U.S. Department of Labor, Employment and Training Administration (1991). This is possible because the NLSY79 classifies each individual's current or most recent job, for 1979 through 2000, according to the 1970 U.S. Census occupational taxonomy. ${ }^{22}$ Following Lakdawalla and Philipson's (2007), we construct a measuring the number of fitness activities (climbing,

\footnotetext{
${ }^{20}$ A drink is defined as "equivalent to a can of beer, a glass of wine, or a shot of hard liquor." Data on binge drinking are also provided in 1985 and number of beverages consumed in 1992; however, the questions are not comparable to those in the other years.

${ }^{21}$ Light/moderate physical activities "cause only light sweating or slight to moderate increases in breathing or heart rate". Vigorous activities "cause heavy sweating or large increases in breathing or heart rate."

Strengthening exercises are those "specifically designed to strengthen ... muscles such as lifting weights or doing calisthenics." Information on the duration of strengthening exercises is not provided.

${ }^{22}$ The 2002 and 2004 NLSY questionnaires use 2000 U.S. Census occupational codes, which are substantially different. Since it is not clear that proposed crosswalks can transform 2000 codes to their 1970 equivalents, we apply information about the current or most recent job from the 2000 year survey to the 2002 and 2004 waves.
} 
reaching, stooping, kneeling, crouching, and crawling) required by the individual's occupation, as well as a strength variables that is an ordinal ranking ranging from one for sedentary occupations to five for occupations with very heavy strength demands. These measures are set to zero for respondents not employed at the survey date.

Our intent is that the included behaviors capture the effects of a broad range of lifestyle factors, but we do not apply a causal interpretation to the coefficient estimates. For example, we make no attempt to resolve the ongoing debate over whether smoking reductions play a role in explaining the growth in obesity (Chou et al., 2004; Gruber and Frakes, 2006). Instead, we incorporate information on tobacco use in hope that it proxies the effects of a constellation of health inputs that may be related to obesity.

Table 1 presents descriptive statistics for BMI, obesity and many of the covariates used in our regression analysis. Results are displayed for the full sample, as well as for gender and SES subsamples. The sample means are generally similar for men and women, although males are heavier, have higher incomes, greater rates of obesity and fewer children. Men also have more physically demanding jobs and lifestyles that are healthier in some ways (like exercising more) but less so in others (they are much more often binge or heavy drinkers and are somewhat more likely to be heavy smokers). The SES differences are more pronounced. Compared to less advantaged individuals, high SES respondents are lighter, much less often obese, more educated, have higher incomes, smoke less and are more physically active. Differences between medium and low SES individuals generally follow the same patterns, except that the middle group has relatively high rates of binge and heavy drinking. The fraction of African-Americans falls monotonically with SES, but Hispanics 
are disproportionately represented among the lowest SES category. These differences motivate the use of multivariate regression analysis.

\section{Age-Related Changes in Body Weight Trends}

Figure 1 and Table 2 provide descriptive evidence of the growth in body weight occurring over time for the NLSY cohort. Unless otherwise noted, all results below incorporate sampling weights to provide nationally representative estimates. Standard errors, shown in parentheses, are corrected for complex survey design using the Taylor-series linearization methods included in Stata (StataCorp, 2005) ${ }^{23}$

Kernel density estimates demonstrate that much of the growth in self-reported BMI occurred in the right-tail of the distribution (Figure 1). This is consistent with evidence using clinical data (Ruhm, 2007) and helps to explain why obesity and severe obesity have increased much faster than average body weight. As shown in Table 2, mean self-reported BMI of NLSY respondents rose 23 percent (from 22.3 to $27.4 \mathrm{~kg} / \mathrm{m}^{2}$ ) between 1981 and 2004, while obesity prevalence increased almost 8 -fold (from 3.0 to 26.5 percent) and class 3 obesity by even more (from $<0.1$ to 2.5 percent). Average BMI and obesity prevalence (but not class 3 obesity) of men is higher than that of women, which initially seems surprising since clinical measures from NHANES show higher female obesity rates (Flegal et al., 2002; Ogden et al., 2006). One explanation for this result, which has been obtained in previous analyses of the NLSY (e.g. by Cawley, 2004), is that self-reported BMI probably understates true values by larger amounts for women than men. Also, since clinical data indicate that females are less often overweight but more frequently obese, an equal BMI underestimate for

\footnotetext{
${ }^{23}$ This is necessary because the NLSY is a multi-stage stratified sample with geographically clustered respondents. Respondents within clusters tend to be relatively similar and standard errors calculated assuming random sampling will be understated. The corrected standard errors require information on the strata and primary sampling unit, which are provided in the restricted NLSY Geocode file.
} 
both genders could cause more clinically obese women to be classified as overweight based on self-report data. ${ }^{24}$ These reporting errors are not a major issue if they are similar across time periods and SES groups, but may be more problematic if this is not the case.

The last three rows of Table 2 show how the results differ with SES, as proxied by maternal education. BMI, obesity and class-3 obesity are more common and increase faster over time for disadvantaged sample members: while average BMI rose $5.4 \mathrm{~kg} / \mathrm{m}^{2}$ and obesity prevalence by 29.2 percentage points between 1981 and 2004 for the lowest SES group, corresponding increases were $5.1 \mathrm{~kg} / \mathrm{m}^{2}$ and 22.2 points for the middle category and $4.5 \mathrm{~kg} / \mathrm{m}^{2}$ and 18.7 points for the most advantaged respondents. ${ }^{25}$

Since BMI and obesity trended upward in the United States throughout the NLSY sample period, the preceding results combine the impact of aging and secular changes in weight. The following procedure was employed to isolate the effects of aging. Data from the NHANES were first used to calculate growth in the average BMI of 24-38 year olds occurring between 1976-80 and 1999-2004. This was next converted to an annualized increase, using a linear trend, and adjustments to eliminate these effects were made to the BMI of each NLSY respondent. Finally, adjusted BMI values were used to calculate mean BMI and compute obesity prevalence. The correction factors were implemented separately for males and females, when examining gender-specific findings. An example helps to illustrate the procedure. NHANES data indicate that the average BMI of 24-38 year olds was $24.734 \mathrm{~kg} / \mathrm{m}^{2}$ in $1976-80$ and $27.609 \mathrm{~kg} / \mathrm{m}^{2}$ in $1999-$

\footnotetext{
${ }^{24}$ Consistent with these possibilities, when we corrected for reporting errors using the procedures detailed above, the average BMI of females in our sample rose 2.0 percent, compared to 0.5 percent for males, while estimated obesity prevalence grew 17.0 percent for women versus 9.0 percent for men.

${ }^{25}$ The disadvantaged also exhibit larger weight gains when SES is proxied by AFQT scores, presence of a father in the household at age 14, highest parental grade completed, or Duncan occupation scores.
} 
2004 , implying an increase of $2.846 \mathrm{~kg} / \mathrm{m}^{2}$, or $0.119 \mathrm{~kg} / \mathrm{m}^{2}$ per year. ${ }^{26}$ The trend variable $T$ takes values ranging from of 0 in 2004, the most recent NLSY interview, to 23 in 1981, the first year for which body weight data are available. Adjusted BMI is therefore calculated by adding $0.119 \mathrm{~kg} / \mathrm{m}^{2} \times T$ to the respondent's self-reported BMI in the specified year. This has the effect of increasing BMI at younger ages, since these correspond to earlier survey dates and reflect the higher body weight that would have been expected using the $2004 \mathrm{BMI}$ distribution. Trends in the NHANES data are calculated for 24-38 year olds because all NLSY sample members were eligible to be interviewed in this age range - the oldest respondents were 24 in 1981 and the youngest were 38 in 2004 - however, the results are not sensitive to this choice. ${ }^{27}$

Separate adjustments were not used for SES subsamples, since NHANES does not contain information on maternal education (our main SES measure). The absence of such adjustments is likely to lead to an understatement of the extent to which SES gradients steepen with age. Previous research indicates that SES-BMI differentials are narrowing over time (Zhang and Wang, 2004; Chang and Lauderdale, 2005), implying that a full adjustment would result in larger (smaller) increases in BMI for high (low) SES individuals at young ages and greater rotation of the gradient. Analysis of NHANES data where SES is proxied by the respondent's education (which, as shown below, is closely linked to SES during childhood), provides additional evidence that the SES gaps have diminished over time. ${ }^{28}$

\footnotetext{
${ }^{26}$ This calculation is based on a 24-year average difference in the timing of interviews in NHANES 2 (1977.5) and the most recent NHANES survey (2001.5).

${ }^{27}$ For instance, the average annual change in BMI was $0.126 \mathrm{~kg} / \mathrm{m}^{2}$ for $16-48$ year olds: the full age range of the NLSY sample.

${ }^{28}$ Between 1976-1980 and 1999-2004, the average BMI of college-educated 24-38 year olds rose 12.8 percent $\left(3.1 \mathrm{~kg} / \mathrm{m}^{2}\right)$, compared to 11.5 percent $\left(2.9 \mathrm{~kg} / \mathrm{m}^{2}\right)$ for their peers who had not attended college.
} 
BMI and obesity prevalence grew rapidly with age. As shown in Figure 2, average BMI rose from 21.6 to $26.9 \mathrm{~kg} / \mathrm{m}^{2}$ between the ages of 18 and 40 , while obesity prevalence increased from 1.0 to 23.2 percent (see Appendix Table A.2 for additional details). Over two-fifths of BMI growth was due to secular trends rather than the effects of aging, so that adjusted BMI rose from 24.3 to $27.3 \mathrm{~kg} / \mathrm{m}^{2}$. This correction had less effect on obesity - the adjusted prevalence was 3.5 percent at age 18 and 24.9 percent for 40-year olds - because the procedure did not change the status of individuals with BMI substantially above or below the threshold.

Figure 3 displays age-related changes in BMI and obesity for gender and SES subgroups, all adjusted for secular trends in average BMI. Four points are noteworthy. First, BMI and obesity rise with age for all subsamples. Second, the age-related increase in BMI is somewhat faster for men than women but growth in obesity prevalence is similar. Generally, the evolution of body weight does not vary sharply with gender over the ages studied. Third, not only do high SES individuals have lower BMI and obesity prevalence but the gradient rotates (steepens with age). For instance, 4.6 percent of lowest SES group are obese at age 18 and 31.3 percent at 40 years of age, while corresponding growth for their high SES counterparts is from 1.9 to 19.6 percent. SES differences are more pronounced for obesity than BMI, reflecting the importance of differences in the right tail of the distribution. Fourth, although the age profiles show weak evidence of concavity, a linear approximation is reasonable, particularly for the age range (24-38) covering all NLSY respondents. 


\section{Empirical Methods}

We next use regression analysis to explore the association between age, SES and body weight. Our basic specification is:

$$
Y_{\mathrm{it}}=\alpha_{0}+\alpha_{1} \boldsymbol{X}_{\mathrm{it}}+\alpha_{2} A G E_{\mathrm{it}}+\alpha_{3} S E S_{\mathrm{i}}+\varepsilon_{\mathrm{it}}
$$

where $Y_{\text {it }}$ is the outcome (BMI or obesity) for individual i at time t, $\boldsymbol{X}$ is a vector of control variables, $A G E$ is the respondent's age at the survey date, $S E S$ is socioeconomic status, and $\varepsilon$ is assumed to be a mean-zero error term. Maternal education is our primary proxy for SES, although other measures are sometimes used. The supplementary covariates vary by model specification. All equations contain survey year dummy variables. We do not initially control for race/ethnicity, respondent education, family income or health behaviors, because they may represent mechanisms through which SES is transmitted and so holding them constant would absorb a portion of the main effect. However, we add them to subsequent models when attempting to understand how SES operates. Equation (1) is estimated for the full sample (with controls for sex) and for subsamples stratified by gender.

The assumption that the SES gradients are age-invariant can be relaxed by estimating:

$$
B M I_{\mathrm{it}}=\alpha_{0}+\alpha_{1} \boldsymbol{X}_{i t}+\alpha_{2} A G E_{\mathrm{it}}+\alpha_{3} S E S_{\mathrm{i}}+\alpha_{4} A G E_{\mathrm{it}} * S E S_{\mathrm{i}}+\varepsilon_{\mathrm{it}}
$$

where $A G E^{*} S E S$ is the interaction between SES and age. For ease of interpretation, we generally express age and SES (when using a continuous proxy) as deviations from the sample averages. As a result, $\hat{\alpha}_{2}, \hat{\alpha}_{3}$ and $\hat{\alpha}_{4}$ indicate marginal effects evaluated at means of the respective variables. Sample weights are incorporated throughout to provide nationally representative estimates and the standard errors account for complex survey design.

We report results of linear probability (LP) models when obesity is the dependent variable. Preliminary analysis revealed similar predicted effects using logit or probit 
estimates, but coefficients from the LP specifications are easier to interpret. This is especially true when including the age-SES interactions, where marginal effects depend on the values of the covariates and the associated coefficients are often misleading. ${ }^{29}$

\section{Econometric Estimates of Age-Profiles and SES-Profiles}

Our initial econometric analysis examines age and SES gradients in BMI and obesity, with additional covariates limited to gender and the survey year. These results are summarized in Table 3. For each specification, column (b) includes an age-SES interaction whereas column (a) does not. The first model controls for low and high SES, with the middle category (12 years of maternal education) constituting the reference group. These estimates correspond to the low, medium and high SES categories in the descriptive analysis above. BMI is predicted to increase by $0.13 \mathrm{~kg} / \mathrm{m}^{2}$ and prevalence of obesity by 0.60 percentage points per year of age (see column 1a). Low SES individuals are anticipated to have a BMI $0.74 \mathrm{~kg} / \mathrm{m}^{2}\left(1.39 \mathrm{~kg} / \mathrm{m}^{2}\right)$ above that of their medium (high) SES peers and a 4.3 (8.4) percentage point greater obesity prevalence. These differences are all statistically significant. The results displayed in specification (1b) indicate that the SES disparities widen with age. For instance, the BMI gap between low and high SES individuals is predicted to rise by $0.040 \mathrm{~kg} / \mathrm{m}^{2}$ per year of age or $0.80 \mathrm{~kg} / \mathrm{m}^{2}$ over 20 years. The expected SES gap in obesity widens even more - by 0.41 percentage points per year or 8.2 points over 20 years. These magnitudes are reasonably consistent with those in the descriptive analysis where, for example, the BMI disparity between low and high SES sample members increased from 0.5

\footnotetext{
${ }^{29} \mathrm{Ai}$ and Norton (2003) show that the coefficients may have the opposite sign as the predicted effect of the interaction on the dependent variable. In preliminary work, we sometimes obtained positive coefficients on the AGE-SES interaction, even though predicted values from the same probit model indicated that the obesity rates of low SES respondents increased with age, relative to their high SES counterparts.
} 
$\mathrm{kg} / \mathrm{m}^{2}$ for 20 -year olds to $1.3 \mathrm{~kg} / \mathrm{m}^{2}$ at age 40 , and the obesity gap rose from 6.2 to 11.7 percentage points (see Table A.2).

The remainder of Table 3 specifies SES as a continuous variable measured by the mother's years of completed schooling. The basic model indicates that BMI (obesity prevalence) rises by a statistically significant $0.12 \mathrm{~kg} / \mathrm{m}^{2}$ ( 0.6 percentage points) per year of age and $0.20 \mathrm{~kg} / \mathrm{m}^{2}$ (1.2 percentage points) for each additional grade completed (columns $2 \mathrm{a}$ and 2b). The age effects are identical to those in model (1a) and the SES gradients accord closely with them. This can be seen by noting that maternal education is 3.2 (6.3) years greater for medium (high) than low SES sample members. Model (2a) predicts that differences of this size result in $0.65(1.27) \mathrm{kg} / \mathrm{m}^{2}$ greater BMI for low than medium (high) SES individuals and a 3.8 (7.6) percentage point disparity in obesity. Corresponding SES gaps predicted by model (1a) were $0.74(1.39) \mathrm{kg} / \mathrm{m}^{2}$ and $4.3(8.4)$ percentage points. Inclusion of an age-SES interaction provides further evidence of rotation of the gradient: the SES disparity is predicted to rise $0.007 \mathrm{~kg} / \mathrm{m}^{2}$ per year of age for BMI and 0.07 percentage points for obesity (see model $2 \mathrm{~b}$ ). To place these in perspective, the BMI gap between respondents at the $10^{\text {th }}$ and $90^{\text {th }}$ percentiles of maternal education $(9$ and 16 years of schooling) is predicted to rise $1.04 \mathrm{~kg} / \mathrm{m}^{2}$ between the ages of 20 and 40 , while the corresponding disparity in obesity prevalence increases 9.7 percentage points.

The continuous SES classification is easy to interpret and uses all available information on the mother's education. A concern, however, is that the findings may be sensitive to the treatment of outliers, particularly if the effects are nonlinear or because a substantial portion of the sample report that their mother received very little schooling. ${ }^{30}$ To address this issue, columns (3a) and (3b) show the results of models where the SES variable

\footnotetext{
${ }^{30}$ Less than six years of maternal education are reported for almost 6 percent of (unweighted) observations.
} 
has been "winsorized" (Angrist and Kruegar, 1999) by setting the minimum (maximum) level of maternal education to $7(16)$ years, corresponding to the $5^{\text {th }}\left(95^{\text {th }}\right)$ percentile. The resulting age profiles are essentially identical to those in models (2a) and (2b), while the SES gradients are 25 to 30 percent larger. This is not surprising, since winsorizing reduces the variance of SES. These estimates suggest that the previous results provide conservative predictions of the SES disparities.

An additional issue is it may be difficult to separate the effects of cohort aging and secular time trends at the top and bottom of the NLSY age range, since observations at these ages will only be obtained early or late in the sample period. For example, data on 18-19 year olds come exclusively from 1981 or 1982 and those on 46-47 year olds are only from 2004. This problem can be reduced by limiting the sample to $24-36$ year olds, for whom sample observations are available in each survey year. These results, shown in columns (4a) and (4b), are fairly similar to those using the full age range. The age coefficients and ageSES interactions are virtually identical to prior BMI equations and are somewhat larger when examining obesity. The SES coefficients are slightly greater as well.

We conducted several other tests of robustness. To examine sensitivity of the results to the exclusion of 3,828 person-year observations (5.4 percent of the sample) lacking information on maternal education, we estimated models including them, with mother's education coded to zero and a missing education dummy variable added. None of the coefficients were substantially affected, with the largest change being a 5 percent reduction for the age parameter in the obesity equation. We allowed for nonlinear age effects, by including controls for age squared and its interaction with SES. The BMI models provided modest evidence of concavity, while the quadratic terms were small and insignificant for 
obesity. ${ }^{31}$ A third set of models removed the effects of secular changes in body weight from individual values, using trend estimates from NHANES data and the adjustment procedures described in section 3 . The BMI estimates were identical to those previously reported and the obesity predictions were similar, although with somewhat stronger age and SES disparities and less rotation of the gradient. ${ }^{32}$ Next, we estimated specifications with BMI and obesity corrected for self-report errors using the methods discussed in section 2 . Coefficients on SES and its interaction with age were essentially unaffected, while the age parameters increased 10 to 17 percent.

We also examined results using the alternative SES proxies: AFQT score of the respondent in 1981, presence of the father in the household at age 14, highest grade completed by the mother or father, and highest Duncan SEI occupation score of the respondent's mother or father. These substitutes yielded results consistent with those obtained using maternal education.

Age and SES gradients in BMI and obesity have been constrained to be the same for males and females up to this point. Such models will be misspecified if there are gender differences in the evolution of body weight over the lifecycle or on the effects of family background. Table 4 examines this issue by providing separate gender-specific estimates. Here and throughout the remaining analysis, we estimate variations of our "preferred" specification, corresponding to columns (2a) and (2b) of Table 3.

BMI and obesity increase with age, decline with SES, and with rotation of the SES gradient for both sexes. The average age effect is similar for males and females but SES

\footnotetext{
${ }^{31}$ In these specifications, age rather than its deviation from sample mean values was controlled for. For BMI, the quadratic on age was statistically significant and indicated that BMI increases through 43 years of age. Similarly, the SES gradient was predicted to widen through age 59.

32 The predicted SES gap in obesity was approximately twice as large for 20 -year olds, as when using the unadjusted data, but essentially the same at age 40 by either method.
} 
disparities are considerably larger for women: the coefficient on maternal education is over twice as big for females as males for BMI and 50 percent greater for obesity in the model without age interactions (columns 1a and 2a). The interaction coefficients indicate that SES gradient rotates much more with age for women (models $1 b$ and $2 b$ ).

Predicted BMI and obesity prevalence for the full sample and gender-stratified subsamples are summarized in Table 5. Individuals are evaluated at 20 and 40 years of age and 9 and 16 years of maternal education. ${ }^{33}$ As noted, BMI and obesity prevalence increase with age for all groups and decline with SES, while the SES-gradient widens with age. These disparities are particularly pronounced for obesity, which depends on outcomes in the right tail of the BMI distribution. For instance, the predicted obesity rate of persons whose mothers had 9 years of schooling almost triples between the ages of 20 and 40 (rising from 9.0 to 24.7 percent). Prevalence rates for their advantaged counterparts - whose mother's had 16 years of education - are expected to be two-thirds as large at age 20 (6.0 percent) but less than half as great by 40 years of age (12.1 percent). Indeed, the obesity rate of 40 -year old high SES individuals is predicted to be only slightly bigger than that for their disadvantaged peers at age 20 .

Table 5 also details greater rotation of the SES gradients expected for women than men. For instance, a 20-year old female whose mother had 9 years of education is 25 percent less likely to be obese than a corresponding male ( 7.7 versus 10.2 percent) but she has essentially identical predicted prevalence at age 40 (24.3 versus 24.7 percent). However, since obesity is projected to grow more slowly with age for advantaged females, a 40 -year old woman whose mother had 16 years of schooling is less than three-fifths as likely to be obese as her male peer (8.6 versus 15.1 percent).

\footnotetext{
${ }^{33}$ These values of maternal education correspond to the $10^{\text {th }}$ and $90^{\text {th }}$ sample percentiles.
} 


\section{Intergenerational Transmission Processes}

The preceding analysis established that BMI and obesity prevalence rise during the transition from early to middle adulthood, that individuals growing up in disadvantaged families weigh more at given ages, and that SES gradients widen with age. We next examine five potential mechanisms through which the effects of SES may propagate across generations: race/ethnicity, education, family income, household composition and individual health behaviors. Specifically, we test whether: 1) some effects of SES operate through or are linked to race-based disparities; 2) high SES children have better adult outcomes because they obtain more education than their disadvantaged peers; 3) holding education constant, persons growing up in advantaged households have relatively high family incomes as adults, with consequent health benefits; 4) SES is correlated with marriage and fertility rates, both of which may in turn be associated with BMI and obesity; 5) SES during the early years is linked to subsequent health behaviors related to body weight and health.

We emphasize several caveats before turning to the data. First, the observed linkages are not necessarily causal. For instance, we will not be able to determine whether race/ethnicity disparities result from genetic differences, measurement error in other covariates (e.g. the quality of education) or omitted characteristics. Similarly, the sources of any SES differences transmitted through education will not be identified, except to the extent that the models directly control for them. For example, we will not uncover whether the impact of schooling operates through differences in discount rates or in the speed of information acquisition on healthy lifestyles. Second, our regressors are often quite limited, raising the likelihood of significant omitted variables biases. For instance, data on leisuretime physical activity are available only late in the sample period (2002 and 2004) and may 
be measured with significant error. ${ }^{34}$ Similarly, the NLSY lacks information on energy intake, a presumably important determinant of body weight. Third, the mechanisms for any observed correlations may be difficult to ascertain, even if the latter are causal. For example, if higher education levels obtained by advantaged children result in lower rates of subsequent obesity, we will not know whether this reflects differences in lifestyles, access to health information, schooling-induced changes in preferences or other unobserved factors.

The data suggest that the beneficial effects of advantaged childhood circumstances on future body weight are primarily transmitted through education and, to a lesser extent, race/ethnicity. The first set of estimates, summarized in Table 6, with additional details in Appendix Table A.3, exclude age-SES interactions and so constrain the SES gradients to be age-invariant. Results in model (1) correspond to those presented previously (in Tables 3 and 4). The full sample SES coefficients fall 26 percent for BMI and 35 percent for obesity when controlling for the respondent's education (specification 2) and by 15 or 16 percent with the inclusion of race/ethnicity covariates (model 3). The two effects are essentially additive, so that the SES coefficient is attenuated 41 percent for BMI and 50 percent for obesity when education and race/ethnicity are simultaneously included (column 4). ${ }^{35}$

Conversely, little of the SES effect appears to propagate through family incomes, household composition, or the available health behaviors. Higher incomes predict lower body weight but the effects are small - attenuating the SES coefficient by 4 to 5 percent when entered in the model alone. Including controls for household composition and health

\footnotetext{
${ }^{34}$ Information on the frequency of exercise was provided through one variable listing the number of times the respondent engaged in the activity and a second indicating the unit of time (daily, weekly, monthly or yearly). However, there appear to be significant coding errors for the latter variable. Similar but less severe problems exist for measuring exercise duration. We made substantial efforts and used reasonable assumptions to correct for these issues but suspect that some measurement error remains.

${ }^{35}$ Also, as shown in Table A.3, the education and race/ethnicity coefficients change little from models (2) or (3) to model (4).
} 
behaviors has even less impact, attenuating the SES parameter less than 1 percent for BMI and below 5 percent for obesity. These effects are minimal because the household composition coefficients are in the expected direction (being single and having more children is associated with higher body weight) but small in magnitude, and with little consistent evidence of greater weight being predicted by the lifestyles common among low SES individuals. ${ }^{36}$ When simultaneously including all supplementary controls in the model (column 5), 45 (56) percent of the SES effect on BMI (obesity) is "explained," with 92 (90) percent of this being due to education and race/ethnicity. ${ }^{37}$

Broadly similar results are obtained when examining men and women separately (see the bottom four rows of Table 6). Education and race/ethnicity attenuate the SES parameters of men by 30 to 47 and 14 to 15 percent, and 45 to 62 percent if entered in combination. When family income, household composition and health behaviors are also controlled for, the magnitude of the SES coefficient declines 49 to 69 percent. Education and race/ethnicity separately attenuate the SES parameter for females by 24 to 30 and 15 to 19 percent, and by 42 to 44 percent when included together. The SES coefficient falls 47 to 50 percent, in absolute value, in the model containing all supplementary covariates.

Next, we allow the SES gradients to vary with age, by adding age-SES interactions to the models. ${ }^{38}$ Since the resulting coefficient estimates are somewhat complicated to interpret, we calculate predicted BMI and obesity prevalence for high and low SES individuals (defined as in Table 5) at 20 and 40 years of age. Differences between the two

\footnotetext{
${ }^{36}$ Specifically, current or past smoking is associated with lower body weight and binge drinking with higher BMI (but not obesity), with inconsistent patterns for the exercise and job-related physical requirement variables.

${ }^{37}$ The results were not materially affected by including a quadratic in income or replacing the continuous education variable with categorical regressors.

${ }^{38}$ Additional interactions of age with respondent education and race/ethnicity were also included in specifications containing main effects for these variables.
} 
groups predicted from the basic model (and previously displayed in Table 5) are labeled the "SES gap." We then calculate expected SES disparities, controlling for supplementary covariates, and compute the share of the initial gap "explained" by them. An example illustrates the procedure. In the basic model, low SES 20-year olds are predicted to have a BMI of $24.134 \mathrm{~kg} / \mathrm{m}^{2}$ compared to $23.309 \mathrm{~kg} / \mathrm{m}^{2}$ for their high SES counterparts, implying a gap of $0.825 \mathrm{~kg} / \mathrm{m}^{2}$. Predicted BMI is 24.030 and $23.339 \mathrm{~kg} / \mathrm{m}^{2}$ for low and high SES 20year olds, after controlling for education, yielding an SES difference of $0.691 \mathrm{~kg} / \mathrm{m}^{2}$, which is 16.2 percent smaller than the initial disparity.

Results of this exercise, displayed in Table 7, confirm the dominant role of education and, to a lesser extent, race/ethnicity in transmitting the effects of family background. Interestingly, the decompositions suggest that the supplementary variables account for virtually the entire relatively small SES differential in obesity for 20 year olds (but much less of the BMI gap). Much larger SES disparities are predicted for both BMI and obesity at age 40 , and just under half of the predicted SES gradient at this age can be accounted for by the combination of controls for respondent education, race/ethnicity, family income, household composition and health behaviors. Schooling and race/ethnicity are individually responsible for 59-63 and 33-38 percent of the explained portion of the gap. Education represents a particularly important propagation mechanism for males, where it independently accounts 39 to 43 percent of the SES gap at age 40, compared to 23 to 24 percent for females.

A possible concern is that the predicted role of education in transmitting the effects of economic advantage may be higher when measuring SES by maternal education than when using other proxies. To address this issue, we replicated the analysis in Tables 6 and 7 using Duncan occupation scores as an alternative indicator of socioeconomic status. This analysis 
confirmed the key role of education and, to a lesser extent, race/ethnicity as transmission mechanisms. For instance, when the SES effects are constrained to be age-invariant (equation 1), the full sample SES coefficient declines 32 (38) percent for BMI (obesity) when controlling for the respondent's education and 22 (17) percent with the inclusion of race/ethnicity covariates. Simultaneously holding race/ethnicity and education constant attenuates the SES parameters by 52 and 55 percent, and including all of the supplementary controls "explains" 54 (61) percent of the SES effect. Qualitatively similar findings are obtained when allowing age-SES interactions or stratifying the sample by sex, except that race/ethnicity is almost as important a mechanism as education for transmitting economic advantage among females (but plays much less of a role for males). ${ }^{39}$

\section{Discussion}

BMI and prevalence obesity rise as individuals transition from early to middle adulthood. The increases are approximately linear over most ages examined, although with some evidence of concavity for the oldest sample members. The econometric estimates indicate that BMI rises about $0.12 \mathrm{~kg} / \mathrm{m}^{2}$ per year of age and obesity prevalence by around 0.6 percentage points per year. These estimates are virtually identical for men and women.

Excess body weight is inversely related to socioeconomic status at all observed points of the lifecycle and these disparities increase with age. Our main proxy for SES is years of schooling obtained by the respondent's mother. The regression results suggest that an additional year of maternal education reduces BMI (obesity) by an average of $0.20 \mathrm{~kg} / \mathrm{m}^{2}$ (1.2 percentage points) and that this effect rises by $0.007 \mathrm{~kg} / \mathrm{m}^{2}(0.07$ points) per year of age, with considerably larger SES disparities predicted for women than men.

\footnotetext{
${ }^{39}$ Controlling for education attenuates the SES coefficient on BMI (obesity) by 36 (38) percent for men and 29 (38) for women. The addition of race/ethnicity covariates does so by 8 (5) percent for males and 28 (30) percent for females.
} 
Preliminary examination of the mechanisms by which the beneficial effects of childhood advantage are translated into future outcomes highlights the importance of educational attainment and race/ethnicity. When entered into the models separately, years of schooling attenuates the average SES effect by 26 to 35 percent and race/ethnicity does so by 15 to 16 percent. In combination, they explain a large majority of the (relatively small) SES gap in the obesity of 20-year olds but less of the (larger) disparity observed at age 40. Little of the SES effect appears to propagate through differences in family income, marital status, number of children, or the included health behaviors.

Evidence that SES disparities in body weight grow with age is consistent with the findings of research focusing on other health outcomes. As with that literature, pathways for these effects are only partially understood. The inclusion of education and race/ethnicity covariates explains (in a statistical sense) close to half of the disparity observed at age 40 and an even larger share of the gap for males. Yet between one-third and three-fifths of the differential predicted for 40-year olds remains unaccounted for after including our full set of controls and we know even less about how education and race/ethnicity operate. Such uncertainty is by no means unique to this study. For instance, Cutler and Lleras-Muney (2006, p.1-2), in their careful review of the evidence, state that "work on the mechanisms underlying the link between health and education has not been conclusive. Not all theories have been tested and ... studies often will conflict with each other." Similarly, racial disparities in health outcomes such as infant mortality are large, persistent and difficult to explain (Stockwell et al., 2005).

We find little evidence that the SES gradients in body weight are related to income or the health behaviors controlled for (drinking, smoking, exercise, and job-related physical 
demands), either directly or mediated through education and race/ethnicity. A possible reason is that these determinants are poorly measured (e.g. information on exercise is only included in the later NLSY survey years). Perhaps even more important, we lack data on other key inputs, such as those related to eating patterns and diet, which may have a larger impact on obesity.

Our findings should also be interpreted in light of several caveats. The self-reports of height and weight contained in the NLSY are likely to be measured with error and these reporting inaccuracies could differ with SES (probably such that our estimates understate the age-related increase in the gradient). Future investigations should experiment more fully with alternative measures of socioeconomic status and, as additional data become available, examine whether the patterns observed here persist later in life. It would also be interesting to link the results obtained for BMI and obesity more closely to other health outcomes, including those directly affected by excess weight. 


\section{$\underline{\text { References }}$}

Adams, Peter, Michael D. Hurd, Daniel McFadden, Angela Merrill, and Tiago Ribeiro. 2003. "Healthy, Wealthy, and Wise? Test for Direct Causal Paths Between Health and Socioeconomic Status" Journal of Econometrics 112(1), January, 3-56.

Ai, Chunrong, and Edward C. Norton. 2003. "Interaction Terms in Logit and Probit Models" Economic Letters 80(1), 123-129.

Allison, David B., Kevin R. Fontaine, JoAnne E. Manson, June Stevens, and Theodore B. VanItallie. 1999. "Annual Deaths Attributable to Obesity in the United States" JAMA 282(16), October 27, 1530-1538.

Andreyeva, Tatiana, Roland Sturm, and Jeanne S. Ringel. 2004. "Moderate and Severe Obesity Have Large Differences in Health Care Costs" Obesity Research 12(12), December, 1936-1943.

Angrist, Joshua D., and Alan B. Kruegar. 1999. "Empirical Strategies in Labor Economics" in Orley Ashenfelter and David Card (eds.) Handbook of Labor Economics, Volume 3A. Amsterdam: Elsevier, 1277-1366.

Averett, Susan, and Sanders Korenman. 1996. "The Economic Reality of the Beauty Myth" Journal of Human Resources 31(2), Spring, 304-330.

Baum, Charles L., and William F. Ford. 2004. "The Wage Effects of Obesity: A Longitudinal Study" Health Economics 13(9), September, 885-899.

Bolton-Smith, Caroline, Mark Woodward, Hugh Turnstall-Pedoe, and Caroline Morrison. 2000. "Accuracy of the Estimated Prevalence of Obesity from Self-Reported Height and Weight in an Adult Scottish Population" Journal of Epidemiology and Community Health 54(2), February, 143-148.

Borghans Lex, and Bart H. H. Golsteyn. 2006. "Time Discounting and the Body Mass Index: Evidence from the Netherlands" Economics and Human Biology 4(1), January, 39-61.

Case, Anne, Darren Lubotsky, and Christina Paxson. 2002. "Economic Status and Health in Childhood: The Origin of the Gradient." American Economic Review 92(5), December, 1308-1334.

Case, Anne, Angela Fertig, and Christina Paxson. 2005. "The Lasting Impact of Childhood Health and Circumstance" Journal of Health Economics 24(2), March, 365-389.

Cawley, John. 2004. "The Impact of Obesity on Wages" Journal of Human Resources 39(2), Spring, 451-474.

Cawley, John, and Richard V. Burkhauser. 2006. "Beyond BMI: The Value of More Accurate Measures of Fatness and Obesity in Social Science Research" Journal of Health Economics, forthcoming.

Center for Human Resource Research. 2004. The National Longitudinal Surveys NLSY

User's Guide, 1979-2004. U. S. Department of Labor, Bureau of Labor Statistics. Columbus, $\mathrm{OH}$ : Center for Human Resource Research, Ohio State University. 
Chang, Virginia W., and Nicholas A. Christakis. 2005. "Income Inequality and Weight Status in US Metropolitan Areas" Social Science and Medicine 61(1), July, 83-96.

Chang, Virginia W., and Diane S. Lauderdale. 2005. "Income Disparities in Body Mass Index and Obesity in the United States, 1971-2002" Archives of Internal Medicine 165(18), October 10, 2122-2128.

Chou, Shin-Yi, Michael Grossman, and Henry Saffer. 2004. "An Economic Analysis of Adult Obesity: Results from the Behavioral Risk Factor Surveillance System” Journal of Health Economics 23(3), May, 565-587.

Classen, Timothy, and Charles Hokayem. 2005. "Childhood Influences on Youth Obesity" Economics and Human Biology 3(2), July, 165-187.

Cox, Brian D., and Margaret J. Whichelow. 1996. "Ratio of Waist Circumference to Height is Better Predictor of Death than Body Mass Index" British Medical Journal 313(7070), December 17, 1487-1488.

Currie, Alison, Michael A. Shields and Stephen Wheatley Price. 2007. "The Child Health/Family Income Gradients: Evidence from England" Journal of Health Economics 26(2), March, 213-232.

Currie, Janet, and Rosemary Hyson. 1999. "Is the Impact of Health Shocks Cushioned by Socioeconomic Status? The Case of Low Birthweight" American Economic Review 89(2), May, 245-250.

Currie, Janet, and Mark Stabile. 2003. "Socioeconomic Status and Child Health: Why Is the Relationship Stronger for Older Children?” American Economic Review 93(5), December, 1813-1823.

Cutler, David M., Edward L. Glaeser, and Jesse M. Shapiro. 2003. "Why Have Americans Become More Obese?” Journal of Economic Perspectives 17(3), Summer, 93-118.

Cutler, David M., and Adriana Lleras-Muney. 2006. "Education and Health: Evaluating Theories and Evidence" National Bureau of Economic Research Working Paper No. 12352, June.

Dalton, M., A. J. Cameron, P. Z. Zimmet, J. E. Shaw, D. Jolley, D. W. Dunstan et al. 2003. "Waist Circumference, Waist-Hip Ratio and Body Mass Index and Their Correlation with Cardiovascular Disease Risk Factors in Australian Adults" Journal of Internal Medicine 254(6), December, 555-563.

Drewnowski, Adam, and S. E. Specter. 2004. "Poverty and Obesity: The Role of Energy Density and Costs" American Journal of Clinical Nutrition 79(1), January, 6-16.

Duncan, Otis Dudley. 1961. “A Socioeconomic Index for All Occupations” In Occupations and Social Status (edited by A. J. Reiss). Glencoe, IL: Free Press, 109-138.

Featherman, David L., Michael Sobel, and David Dickens. 1975. "A Manual for Coding Occupations and Industries into Detailed 1970 Categories and Listing of 1970-Basis Duncan Socioeconomic and NORC Prestige Scores" The University of Wisconsin, Center for Demography and Ecology: Working Paper Number 75-1. 
Finkelstein, Eric A., Ian C. Fiebelkorn, and Guijing Wang. 2003. "National Medical Spending Attributable to Overweight and Obesity: How Much, and Who's paying" Health Affairs May 14; web exclusive, w3.219-w3.226.

Flegal, Katherine M., Rong Wei, and Cynthia Ogden. 2002. "Weight-for-Stature Compared with Body Mass Index-for-Age Growth Charts for the United States from the Centers for Disease Control and Prevention" American Journal of Clinical Nutrition 75(4), April, 761 766.

Flegal Katherine M., Barry I. Graubard, David F. Williamson, and Mitchell H. Gail. 2005. "Excess Deaths Associated with Underweight, Overweight, and Obesity" JAMA 293(15), April 20, 1861-1867.

Fontaine, Kevin R., David T. Redden, Chenxi Wang, Andrew O. Westfall, and David B. Allison. 2003. "Years of Life Lost Due to Obesity" JAMA 289(2), January 8, 187-193.

Fuchs, Victor R. 2004. "Reflections on the Socio-economic Correlates of Health" Journal of Health Economics 23(4), July, 653-661.

Geronimus, Arline T., Margaret Hicken, Danya Keene and John Bound. 2006. "'Weathering' and Age Patterns of Allostatic Load Scores Among Blacks and Whites in the United States" American Journal of Public Health 96(5), May, 826-833.

Goodman, Elizabeth, Beth R. Hinden, and Seema Khandelwal. 2000. "Accuracy of Teen and Parental Reports of Obesity and Body Mass Index” Pediatrics 106(1), July, 52-58.

Gruber, Jonathan, and Michael Frakes. 2006. "Does Falling Smoking Lead to Rising Obesity?” Journal of Health Economics 25(2), March, 183-197.

Guo, Shumei Sun, Wei Wu, William Cameron Chumlea, and Alex F. Roche. 2002.

"Predicting Overweight and Obesity in Adulthood from Body Mass Index Values in Childhood and Adolescence" American Journal of Clinical Nutrition 76(3), September, 653658.

Kuczmarski, Robert J., Cynthia L. Ogden, Laurence M. Grummer-Strawn, et al. 2000. CDC Growth Charts: United States. Advance Data from Vital and Health Statistics, no. 314. Hyattsville, MD: National Center for Health Statistics.

Kuczmarski, Marie Fanelli, Robert J. Kuczmarski, and Matthew Najjar. 2001. "Effects of Age on Validity of Self-Reported Height, Weight, and Body Mass Index: Findings from the Third Health and Nutrition Examination Survey, 1988-1994" Journal of the American Dietetic Association 101(1), January, 28-34.

Lakdawalla, Darius, and Tomas Philipson. 2007. "Labor Supply and Weight" The Journal of Human Resources 42 (1), 85-116.

Marmot, M., G. D. Smith, S. Stansfeld, C. Patel, F. North, J. Head, I. White, E. Brunner, and A. Feeny. 1991. "Health Inequalities Among British Civil Servants: The Whitehall II Study" Lancet 337(8754), June 8, 1387-93.

McTigue, Kathleen M., Joanne M.Garrett, and Barry M. Popkin. 2002. "The Natural History of the Development of Obesity in a Cohort of Young U.S. Adults Between 1981 and 1998" Annals of Internal Medicine 136(12), June 18, 857-864. 
McTigue Kathleen, Joseph C. Larson, Alice Valoski, Greg Burke, Jane Kotchen, Cora E. Lewis, Marcia L. Stefanick, Linda Van Horn, and Lewis Kuller. 2006. "Mortality Outcomes and Cardiac and Vascular Outcomes in Extremely Obese Women" JAMA 296(1), July 5, 7986.

Mokdad, Ali H., Barbara A. Bowman, Earl S. Ford, Frank Vinicor, James S. Marks, and Jeffrey P. Koplan. 2001. "The Continuing Epidemic of Obesity and Diabetes in the United States" JAMA 286(10), September 21, 1195-1200.

Must, Aviva, Jennifer Spadano, Eugenie H. Coakley, Alison E. Field, Graham Colditz, and William H. Dietz. 1999. "The Disease Burden Associated With Overweight and Obesity" JAMA 282(16), October 27, 1523-1529.

National Heart, Lung, and Blood Institute. 1998. Clinical guidelines on the identification, evaluation, and treatment of overweight and obesity in adults: the evidence report.

Washington D.C.: US Government Printing Office.

Noonan, Kelly, Nancy E. Reichman, and Hope Corman. 2005. 'New Fathers' Labor Supply: Does Child Health Matter?” Social Science Quarterly 86(S1), December, 1399-1417.

Ogden, Cynthia L., Margaret D. Carroll, Lester R. Curtin, Margaret A. McDowell, Carolyn J. Tabak, and Katherine M. Flegal. 2006. "Prevalence of Overweight and Obesity in the United States, 1999-2004” JAMA 295(13), April 5, 1549-1555.

Plankey, Michael W., June Stevens, Katherine M. Flegal, and Philip F. Rust. 1997.

"Prediction Equations Do Not Eliminate Systematic Error in Self-Reported Body Mass Index" Obesity Research 5(4), July, 308-14.

Powers, Elizabeth T. 2003. "Children's Health and Maternal Work Activity: Estimates Under Alternative Disability Definitions” Journal of Human Resources 38(3), Summer, 522-556.

Quesenberry, Charles P., Bette Caan, and Alice Jacobson. 1998. “Obesity, Health Services Use, and Health Care Costs Among Members of a Health Maintenance Organization" Archives of Internal Medicine 158(5), March 9, 466-472.

Ruhm, Christopher J. 2005. "Healthy Living in Hard Times" Journal of Health Economics 24(2), March 341-63.

Ruhm, Christopher J. 2007. "Prevalence and Trends of Extreme Obesity Among US Children, Adolescents and Adults, 1960-2004" mimeo, University of North Carolina at Greensboro, January.

Smith, James P. 2004. "Unraveling the SES-Health Connection” in Waite, Linda J. (ed.). Aging, Health, and the Public Policy: Demographic and Economic Perspectives, Supplement to Population and Development Studies 30, 108-132.

Smith, Patricia K., Barry Bogin, and David Bishai. 2005. "Are Time Preference and Body Mass Index Associated? Evidence from the National Longitudinal Survey of Youth" Economics and Human Biology 3(2), May, 259-270.

Sönmez, K., M. Akcakoyun, A. Akcay, D. Demir, N. E. Duran, M. Gencbay et al. 2003. "Which Method Should be Used to Determine the Obesity, in Patients with Coronary Artery Disease? (Body Mass Index, Waist Circumference, or Waist-Hip Ratio)" International Journal of Obesity 27(3), March, 341-346. 
Spencer, Elizabeth A., Paul N. Appleby, Gwyneth K. Davey, and Timothy J. Key. 2002. "Validity of Self-Reported Height and Weight in 4808 EPIC-Oxford Participants" Public Health Nutrition 54(4), August 2002, 561-5.

StataCorp. 2005. Stata User's Guide. College Station, TX: STATA Press.

Stevens, G., and David L. Featherman. 1981. "A Revised Socioeconomic Index for Occupational Status" Social Science Research 10, 364-393.

Stockwell, Edward D., Franklin W. Goza, and Kelly S. Belistreri. 2005. "Infant Mortality and Socioeconomic Status: New Bottle, Same Old Wine" Population Research and Policy Review 24(4), August, 387-399.

Strauss, R. S. 1999. "Comparison of Measured and Self-Reported Weight and Height in a Cross-Sectional Sample of Young Adolescents" International Journal of Obesity 23(8), August, 904-908.

U.S. Department of Labor, Employment and Training Administration. 1991. Dictionary of Occupational Titles, Revised Fourth Edition. Washington D.C.: U.S. Government Printing Office.

Whitaker, Robert C., Jeffrey A. Wright, Margaret S. Pepe, Kristy D. Seidel, and William H. Dietz. 1997. "Predicting Obesity in Young Adulthood from Childhood and Parental Obesity" New England Journal of Medicine 337(13), September 25, 869-873.

World Health Organization. 1997. Obesity: Preventing and managing the global epidemic. report of a WHO consultation on obesity. Geneva, Switzerland: World Health Organization.

Zhang, Qi, and Youfa Wang. 2004. "Trends in the Association between Obesity and Socioeconomic Status in U.S. Adults: 1971 to 2000" Obesity Research 12(10), October, $1622-1632$. 
Table 1: Descriptive Statistics by Gender and Socioeconomic Status

\begin{tabular}{|c|c|c|c|c|c|c|}
\hline \multirow{2}{*}{ Variable } & \multirow{2}{*}{$\begin{array}{c}\text { Full } \\
\text { Sample }\end{array}$} & \multicolumn{2}{|c|}{ Gender } & \multicolumn{3}{|c|}{ SES } \\
\hline & & Male & Female & Low & Medium & High \\
\hline BMI & $\begin{array}{l}25.2 \\
(0.1)\end{array}$ & $\begin{array}{l}26.0 \\
(0.1)\end{array}$ & $\begin{array}{l}24.3 \\
(0.1)\end{array}$ & $\begin{array}{l}25.8 \\
(0.1)\end{array}$ & $\begin{array}{l}25.1 \\
(0.1)\end{array}$ & $\begin{array}{l}24.4 \\
(0.2)\end{array}$ \\
\hline Obese & $\begin{array}{l}14.5 \% \\
(0.5 \%)\end{array}$ & $\begin{array}{l}15.4 \% \\
(0.8 \%)\end{array}$ & $\begin{array}{l}13.4 \% \\
(0.6 \%)\end{array}$ & $\begin{array}{l}18.4 \% \\
(0.9 \%)\end{array}$ & $\begin{array}{l}14.2 \% \\
(0.7 \%)\end{array}$ & $\begin{array}{l}10.0 \% \\
(0.9 \%)\end{array}$ \\
\hline Age (Years) & $\begin{array}{l}31.2 \\
(0.0)\end{array}$ & $\begin{array}{l}31.0 \\
(0.1)\end{array}$ & $\begin{array}{l}31.5 \\
(0.1)\end{array}$ & $\begin{array}{l}31.3 \\
(0.1)\end{array}$ & $\begin{array}{l}31.2 \\
(0.1)\end{array}$ & $\begin{array}{l}31.2 \\
(0.1)\end{array}$ \\
\hline Male & $\begin{array}{l}53.1 \% \\
(0.8 \%)\end{array}$ & -- & -- & $\begin{array}{l}48.8 \% \\
(1.4 \%)\end{array}$ & $\begin{array}{l}55.2 \% \\
(1.3 \%)\end{array}$ & $\begin{array}{l}53.6 \% \\
(1.7 \%)\end{array}$ \\
\hline Black & $\begin{array}{l}13.1 \% \\
(1.6 \%)\end{array}$ & $\begin{array}{l}12.8 \% \\
(1.6 \%)\end{array}$ & $\begin{array}{l}13.4 \% \\
(1.6 \%)\end{array}$ & $\begin{array}{l}22.2 \% \\
(2.7 \%)\end{array}$ & $\begin{array}{l}9.1 \% \\
(1.3 \%)\end{array}$ & $\begin{array}{c}8.0 \% \\
(1.4 \%)\end{array}$ \\
\hline Hispanic & $\begin{array}{c}5.3 \% \\
(0.8 \%)\end{array}$ & $\begin{array}{c}5.3 \% \\
(0.8 \%)\end{array}$ & $\begin{array}{c}5.2 \% \\
(0.8 \%)\end{array}$ & $\begin{array}{l}12.0 \% \\
(1.8 \%)\end{array}$ & $\begin{array}{l}2.3 \% \\
(0.4 \%)\end{array}$ & $\begin{array}{c}2.3 \% \\
(0.5 \%)\end{array}$ \\
\hline Married & $\begin{array}{l}52.7 \% \\
(0.8 \%)\end{array}$ & $\begin{array}{l}52.2 \% \\
(0.9 \%)\end{array}$ & $\begin{array}{l}53.3 \% \\
(1.0 \%)\end{array}$ & $\begin{array}{l}50.8 \% \\
(1.2 \%)\end{array}$ & $\begin{array}{l}54.4 \% \\
(0.9 \%)\end{array}$ & $\begin{array}{l}52.3 \% \\
(1.2 \%)\end{array}$ \\
\hline Number of Children & $\begin{array}{c}1.14 \\
(0.02)\end{array}$ & $\begin{array}{c}1.03 \\
(0.02)\end{array}$ & $\begin{array}{c}1.26 \\
(0.03)\end{array}$ & $\begin{array}{c}1.38 \\
(0.03)\end{array}$ & $\begin{array}{c}1.08 \\
(0.03)\end{array}$ & $\begin{array}{c}0.90 \\
(0.04)\end{array}$ \\
\hline Education of Respondent (Years) & $\begin{array}{l}13.2 \\
(0.1)\end{array}$ & $\begin{array}{l}13.2 \\
(0.1)\end{array}$ & $\begin{array}{l}13.3 \\
(0.1)\end{array}$ & $\begin{array}{l}12.1 \\
(0.1)\end{array}$ & $\begin{array}{l}13.3 \\
(0.1)\end{array}$ & $\begin{array}{l}14.8 \\
(0.1)\end{array}$ \\
\hline Family Income $(\$ 1,000 \mathrm{~s})$ & $\begin{array}{l}64.8 \\
(1.5)\end{array}$ & $\begin{array}{l}66.2 \\
(1.9)\end{array}$ & $\begin{array}{l}63.1 \\
(1.6)\end{array}$ & $\begin{array}{l}48.4 \\
(1.4)\end{array}$ & $\begin{array}{l}65.6 \\
(2.0)\end{array}$ & $\begin{array}{l}87.6 \\
(3.4)\end{array}$ \\
\hline Education of Mother (Years) & $\begin{array}{l}11.8 \\
(0.1)\end{array}$ & $\begin{array}{l}11.9 \\
(0.1)\end{array}$ & $\begin{array}{l}11.7 \\
(0.1)\end{array}$ & $\begin{array}{c}8.8 \\
(0.1)\end{array}$ & $\begin{array}{l}12.0 \\
(0.0)\end{array}$ & $\begin{array}{l}15.1 \\
(0.1)\end{array}$ \\
\hline Ever Smoked ( $\geq 100$ cigarettes) & $\begin{array}{l}45.8 \% \\
(0.9 \%)\end{array}$ & $\begin{array}{l}45.0 \% \\
(1.2 \%)\end{array}$ & $\begin{array}{l}46.6 \% \\
(1.2 \%)\end{array}$ & $\begin{array}{l}51.8 \% \\
(1.6 \%)\end{array}$ & $\begin{array}{l}45.1 \% \\
(1.3 \%)\end{array}$ & $\begin{array}{l}37.0 \% \\
(1.6 \%)\end{array}$ \\
\hline Current Smoker & $\begin{array}{l}32.2 \% \\
(0.7 \%)\end{array}$ & $\begin{array}{l}31.8 \% \\
(1.1 \%)\end{array}$ & $\begin{array}{l}32.5 \% \\
(1.0 \%)\end{array}$ & $\begin{array}{l}38.7 \% \\
(1.4 \%)\end{array}$ & $\begin{array}{l}31.4 \% \\
(1.0 \%)\end{array}$ & $\begin{array}{l}23.4 \% \\
(1.3 \%)\end{array}$ \\
\hline Heavy Smoker ( $\geq 20 /$ day) & $\begin{array}{l}17.6 \% \\
(0.7 \%)\end{array}$ & $\begin{array}{l}19.0 \% \\
(1.0 \%)\end{array}$ & $\begin{array}{l}16.0 \% \\
(0.8 \%)\end{array}$ & $\begin{array}{l}22.1 \% \\
(1.3 \%)\end{array}$ & $\begin{array}{l}17.3 \% \\
(0.9 \%)\end{array}$ & $\begin{array}{l}11.6 \% \\
(1.3 \%)\end{array}$ \\
\hline Binge Drinker in Last Month & $\begin{array}{l}34.1 \% \\
(0.9 \%)\end{array}$ & $\begin{array}{l}44.9 \% \\
(1.0 \%)\end{array}$ & $\begin{array}{l}21.9 \% \\
(0.9 \%)\end{array}$ & $\begin{array}{l}32.3 \% \\
(1.2 \%)\end{array}$ & $\begin{array}{l}35.7 \% \\
(1.3 \%)\end{array}$ & $\begin{array}{l}32.5 \% \\
(1.4 \%)\end{array}$ \\
\hline Heavy Drinker ( $\geq 60$ last month) & $\begin{array}{c}9.2 \% \\
(0.4 \%)\end{array}$ & $\begin{array}{l}13.6 \% \\
(0.6 \%)\end{array}$ & $\begin{array}{c}4.1 \% \\
(0.3 \%)\end{array}$ & $\begin{array}{l}7.8 \% \\
(0.5 \%)\end{array}$ & $\begin{array}{l}9.9 \% \\
(0.6 \%)\end{array}$ & $\begin{array}{c}9.0 \% \\
(0.7 \%)\end{array}$ \\
\hline Physically Inactive & $\begin{array}{l}12.3 \% \\
(0.7 \%)\end{array}$ & $\begin{array}{l}10.1 \% \\
(0.8 \%)\end{array}$ & $\begin{array}{l}14.8 \% \\
(0.9 \%)\end{array}$ & $\begin{array}{l}16.6 \% \\
(1.3 \%)\end{array}$ & $\begin{array}{l}10.4 \% \\
(0.9 \%)\end{array}$ & $\begin{array}{c}9.8 \% \\
(1.1 \%)\end{array}$ \\
\hline Moderately Active & $\begin{array}{r}12.8 \% \\
(0.6 \%)\end{array}$ & $\begin{array}{l}10.9 \% \\
(0.7 \%)\end{array}$ & $\begin{array}{l}15.0 \% \\
(0.9 \%)\end{array}$ & $\begin{array}{l}12.4 \% \\
(1.0 \%)\end{array}$ & $\begin{array}{l}13.0 \% \\
(0.9 \%)\end{array}$ & $\begin{array}{l}13.9 \% \\
(1.5 \%)\end{array}$ \\
\hline Physically Active & $\begin{array}{l}29.9 \% \\
(0.7 \%)\end{array}$ & $\begin{array}{l}26.6 \% \\
(1.1 \%)\end{array}$ & $\begin{array}{l}33.6 \% \\
(1.1 \%)\end{array}$ & $\begin{array}{l}30.5 \% \\
(1.3 \%)\end{array}$ & $\begin{array}{l}30.7 \% \\
(1.1 \%)\end{array}$ & $\begin{array}{l}27.3 \% \\
(1.7 \%)\end{array}$ \\
\hline Vigorous Physical Activity & $\begin{array}{l}45.1 \% \\
(0.9 \%)\end{array}$ & $\begin{array}{l}52.5 \% \\
(1.3 \%)\end{array}$ & $\begin{array}{l}36.7 \% \\
(1.2 \%)\end{array}$ & $\begin{array}{l}40.6 \% \\
(1.6 \%)\end{array}$ & $\begin{array}{l}46.0 \% \\
(1.3 \%)\end{array}$ & $\begin{array}{l}49.2 \% \\
(2.1 \%)\end{array}$ \\
\hline Strengthening Exercises & $\begin{array}{l}38.1 \% \\
(0.7 \%)\end{array}$ & $\begin{array}{l}40.0 \% \\
(1.1 \%)\end{array}$ & $\begin{array}{l}35.9 \% \\
(1.1 \%)\end{array}$ & $\begin{array}{l}31.2 \% \\
(1.3 \%)\end{array}$ & $\begin{array}{l}39.3 \% \\
(1.2 \%)\end{array}$ & $\begin{array}{l}45.3 \% \\
(1.5 \%)\end{array}$ \\
\hline Job-Related Fitness Demands & 1.564 & 1.689 & 1.423 & 1.546 & 1.585 & 1.558 \\
\hline
\end{tabular}




\begin{tabular}{lcccccc} 
& $(0.010)$ & $(0.011)$ & $(0.014)$ & $(0.020)$ & $(0.012)$ & $(0.016)$ \\
Job-Related Strength Demands & 0.577 & 0.648 & 0.498 & 0.572 & 0.578 & 0.591 \\
& $(0.006)$ & $(0.009)$ & $(0.008)$ & $(0.012)$ & $(0.008)$ & $(0.014)$ \\
Sample Size & 70,908 & 37,470 & 33,438 & 27,095 & 28,260 & 11,725 \\
\hline
\end{tabular}

Note: Table displays descriptive statistics from the National Longitudinal Survey of Youth for those years where information on body weight was obtained (1981, 1982, 1985, 1986, 1988, 1989, 1990, 1992, 1993, 1994, 1996, 1998, 2000, 2002 and 2004). Standard errors, corrected for population weights and complex survey design, are displayed in parentheses. Body Mass Index (BMI) is obtained from self-reported information on weight and height. Obesity is defined as BMI $\geq 30$. Low, middle and high SES refer to respondents whose mothers have completed $<12,12$ or $>12$ years of education. Family income is measured in 2004-year dollars. Data on alcohol consumption is from 1982-1984, 1988, 1989, 1994 and 2002; that on smoking is from 1984, 1992, 1994 and 1998. These health behaviors refer to either the first or the most recent previous interview for which the information was obtained. Binge drinking refers to consuming six or more drinks in a single session and heavy drinking to consumption of more than 60 drinks per month. Data on leisure-time physical activity is from 2002 and 2004 and refers to the month prior to the survey. Respondents are defined as physically inactive if they exercise less than one hour per week and moderately active if they did so 1 to 2 hours weekly. Vigorous exercisers engage in more than 2 hours of vigorous physical activity per week and those who are physically active participate in more than two hours per week of all types of exercise but less than 2 hours of vigorous activities. Strengthening exercise indicates participation in these activities at least once per week. Data on jobrelated fitness and strength demands are collected from 1981 through 2000; the former refers to the number of fitness activities required by the occupation and the latter is the score, ranging from one to five, on an ordinal index. 
Table 2: Body Mass Index and Obesity By Survey Year and Sample Characteristics

\begin{tabular}{|c|c|c|c|c|c|c|}
\hline \multirow[t]{2}{*}{ Group } & \multicolumn{2}{|c|}{ Body Mass Index (BMI) } & \multicolumn{2}{|c|}{ Obese (BMI $\geq 30)$} & \multicolumn{2}{|c|}{ Class 3 Obesity $(\mathrm{BMI} \geq 40)$} \\
\hline & 1981 & 2004 & 1981 & 2004 & 1981 & 2004 \\
\hline Full Sample & $\begin{array}{l}22.3 \\
(0.1)\end{array}$ & $\begin{array}{l}27.4 \\
(0.1)\end{array}$ & $\begin{array}{c}3.0 \% \\
(0.3 \%)\end{array}$ & $\begin{array}{l}26.5 \% \\
(0.8 \%)\end{array}$ & $\begin{array}{c}0.05 \% \\
(0.03 \%)\end{array}$ & $\begin{array}{c}2.53 \% \\
(0.25 \%)\end{array}$ \\
\hline Males & $\begin{array}{l}23.2 \\
(0.1)\end{array}$ & $\begin{array}{l}28.2 \\
(0.1)\end{array}$ & $\begin{array}{c}3.5 \% \\
(0.4 \%)\end{array}$ & $\begin{array}{l}28.8 \% \\
(1.1 \%)\end{array}$ & $\begin{array}{c}0.04 \% \\
(0.04 \%)\end{array}$ & $\begin{array}{c}2.00 \% \\
(0.04 \%)\end{array}$ \\
\hline Females & $\begin{array}{l}21.4 \\
(0.1)\end{array}$ & $\begin{array}{l}26.6 \\
(0.1)\end{array}$ & $\begin{array}{c}2.4 \% \\
(0.4 \%)\end{array}$ & $\begin{array}{l}24.1 \% \\
(1.0 \%)\end{array}$ & $\begin{array}{c}0.06 \% \\
(0.04 \%)\end{array}$ & $\begin{array}{c}3.05 \% \\
(0.39 \%)\end{array}$ \\
\hline Low SES & $\begin{array}{l}22.7 \\
(0.1)\end{array}$ & $\begin{array}{l}28.1 \\
(0.2)\end{array}$ & $\begin{array}{c}3.4 \% \\
(0.5 \%)\end{array}$ & $\begin{array}{l}32.6 \% \\
(1.3 \%)\end{array}$ & $\begin{array}{c}0.14 \% \\
(0.09 \%)\end{array}$ & $\begin{array}{c}2.95 \% \\
(0.43 \%)\end{array}$ \\
\hline Medium SES & $\begin{array}{l}22.3 \\
(0.1)\end{array}$ & $\begin{array}{l}27.4 \\
(0.1)\end{array}$ & $\begin{array}{c}3.3 \% \\
(0.4 \%)\end{array}$ & $\begin{array}{l}25.5 \% \\
(1.1 \%)\end{array}$ & $\begin{array}{c}0.00 \% \\
(0.00 \%)\end{array}$ & $\begin{array}{c}2.59 \% \\
(0.40 \%)\end{array}$ \\
\hline High SES & $\begin{array}{l}22.0 \\
(0.1)\end{array}$ & $\begin{array}{l}26.5 \\
(0.2)\end{array}$ & $\begin{array}{c}1.5 \% \\
(0.5 \%)\end{array}$ & $\begin{array}{l}20.2 \% \\
(1.7 \%)\end{array}$ & $\begin{array}{c}0.00 \% \\
(0.00 \%)\end{array}$ & $\begin{array}{c}1.80 \% \\
(0.47 \%)\end{array}$ \\
\hline
\end{tabular}

Note: See note on Table 1. Information is from the 1981 and 2004 years of the National Longitudinal Survey of Youth (NLSY). Samples sizes in 1981 are 4,628, 2,498, 2,130, 1,716, 1,861 and 806 for the full sample, males, females, low, medium and high SES respondents. Corresponding sample sizes are 5,022, 2,498, 2,524, 1,929, 1,997 and 824 in 2004. The sample sizes differ across time periods because females who are pregnant or have given birth in the last year are excluded. 
Table 3: Econometric Estimates of Age and SES Gradients in BMI and Obesity

\begin{tabular}{|c|c|c|c|c|c|c|c|c|c|}
\hline Regressor & (1a) & (1b) & Regressor & (2a) & (2b) & (3a) & (3b) & (4a) & (4b) \\
\hline \multicolumn{10}{|c|}{ Body Mass Index } \\
\hline Age & $\begin{array}{c}0.1227 \\
(0.0285)\end{array}$ & $\begin{array}{c}0.1176 \\
(0.0288)\end{array}$ & Age & $\begin{array}{c}0.1225 \\
(0.0286)\end{array}$ & $\begin{array}{c}0.1221 \\
(0.0285)\end{array}$ & $\begin{array}{c}0.1233 \\
(0.0286)\end{array}$ & $\begin{array}{c}0.1231 \\
(0.0285)\end{array}$ & $\begin{array}{c}0.1274 \\
(0.0313)\end{array}$ & $\begin{array}{c}0.1273 \\
(0.0312)\end{array}$ \\
\hline Low SES & $\begin{array}{c}0.7370 \\
(0.1685)\end{array}$ & $\begin{array}{c}0.7356 \\
(0.1684)\end{array}$ & SES & $\begin{array}{l}-0.2017 \\
(0.0242)\end{array}$ & $\begin{array}{c}-0.2009 \\
(0.0241)\end{array}$ & $\begin{array}{c}-0.2549 \\
(0.0291)\end{array}$ & $\begin{array}{c}-0.2544 \\
(0.0291)\end{array}$ & $\begin{array}{c}-0.2145 \\
(0.0251)\end{array}$ & $\begin{array}{c}-0.2143 \\
(0.0251)\end{array}$ \\
\hline $\begin{array}{l}\text { Age } x \\
\text { Low SES }\end{array}$ & & $\begin{array}{c}0.0268 \\
(0.0094)\end{array}$ & Age $x$ SES & & $\begin{array}{c}-0.0074 \\
(0.0015)\end{array}$ & & $\begin{array}{c}-0.0090 \\
(0.0018)\end{array}$ & & $\begin{array}{c}-0.0073 \\
(0.0021)\end{array}$ \\
\hline High SES & $\begin{array}{c}-0.6514 \\
(0.1981)\end{array}$ & $\begin{array}{c}-0.6526 \\
(0.1985)\end{array}$ & & & & & & & \\
\hline \multirow[t]{2}{*}{$\begin{array}{l}\text { Age } x \\
\text { High SES }\end{array}$} & & $\begin{array}{c}-0.0131 \\
(0.0120)\end{array}$ & & & & & & & \\
\hline & \multicolumn{3}{|c|}{ Obesity Prevalence } & & & & & & \\
\hline Age & $\begin{array}{c}0.0060 \\
(0.0019)\end{array}$ & $\begin{array}{c}0.0055 \\
(0.0019)\end{array}$ & Age & $\begin{array}{c}0.0060 \\
(0.0019)\end{array}$ & $\begin{array}{c}0.0059 \\
(0.0019)\end{array}$ & $\begin{array}{c}0.0060 \\
(0.0019)\end{array}$ & $\begin{array}{c}0.0060 \\
(0.0019)\end{array}$ & $\begin{array}{c}0.0081 \\
(0.0022)\end{array}$ & $\begin{array}{c}0.0081 \\
(0.0021)\end{array}$ \\
\hline Low SES & $\begin{array}{c}0.0432 \\
(0.0114)\end{array}$ & $\begin{array}{c}0.0430 \\
(0.0114)\end{array}$ & SES & $\begin{array}{c}-0.0120 \\
(0.0015)\end{array}$ & $\begin{array}{c}-0.0120 \\
(0.0014)\end{array}$ & $\begin{array}{c}-0.0153 \\
(0.0017)\end{array}$ & $\begin{array}{c}-0.0152 \\
(0.0017)\end{array}$ & $\begin{array}{l}-0.0129 \\
(0.0016)\end{array}$ & $\begin{array}{c}-0.0129 \\
(0.0016)\end{array}$ \\
\hline $\begin{array}{l}\text { Age } x \\
\text { Low SES }\end{array}$ & & $\begin{array}{l}0.0027 \\
(0.008)\end{array}$ & Age $x$ SES & & $\begin{array}{c}-6.9 \mathrm{E}-4 \\
(1.2 \mathrm{E}-4)\end{array}$ & & $\begin{array}{c}-8.8 \mathrm{E}-4 \\
(1.4 \mathrm{E}-4)\end{array}$ & & $\begin{array}{l}-7.9 \mathrm{E}-4 \\
(2.0 \mathrm{E}-4)\end{array}$ \\
\hline High SES & $\begin{array}{l}-0.0407 \\
(0.0120)\end{array}$ & $\begin{array}{c}-0.0408 \\
(0.0121)\end{array}$ & & & & & & & \\
\hline $\begin{array}{l}\text { Age } x \\
\text { High SES }\end{array}$ & & $\begin{array}{c}-0.0014 \\
(0.009)\end{array}$ & & & & & & & \\
\hline Comment & Trichot & us SES & & Contin & us SES & Winso & ed SES & $24-38$ & ar Olds \\
\hline
\end{tabular}


Note: See note on Table 1. Linear probability models are used to estimate the relationship between age, socioeconomic status and their interaction on obesity. Sample weights are incorporated in the estimates and standard errors, reported in parentheses, are adjusted to account for complex survey design. Model (1) uses a trichotomous variable where low, medium and high SES refer to $<12,12$, and $>12$ years of schooling completed by the respondent's mother. SES is proxied by years of education completed by the respondent's mother in models (2) and (4). This SES variable is winsorized in model (3) by setting years of education equal to 7 (16) for persons reporting that their mothers had less (more) schooling than this amount; these correspond to the $5^{\text {th }}$ and $95^{\text {th }}$ percentiles of the distribution. Age and SES are measured as deviations from the sample means. Model (4) limits the sample to 24-38 year olds. The sample is limited to observations with information available on maternal education. Sample sizes are 67,047 for the full sample and 41,254 for 24-38 year olds. The regressions also include controls for gender and the interview year. 
Table 4: Econometric Estimates of Age and SES Gradients by Gender

\begin{tabular}{|c|c|c|c|c|}
\hline \multirow[t]{2}{*}{ Regressor } & \multicolumn{2}{|c|}{ Males } & \multicolumn{2}{|c|}{ Females } \\
\hline & (1a) & (1b) & (2a) & (2b) \\
\hline \multicolumn{5}{|c|}{ Body Mass Index } \\
\hline Age & $\begin{array}{c}0.1222 \\
(0.0396)\end{array}$ & $\begin{array}{c}0.1221 \\
(0.0396)\end{array}$ & $\begin{array}{c}0.1179 \\
(0.0415)\end{array}$ & $\begin{array}{c}0.1173 \\
(0.0414)\end{array}$ \\
\hline SES & $\begin{array}{l}-0.1215 \\
(0.0279)\end{array}$ & $\begin{array}{c}-0.1212 \\
(0.0277)\end{array}$ & $\begin{array}{c}-0.2877 \\
(0.0390)\end{array}$ & $\begin{array}{c}-0.2865 \\
(0.0399)\end{array}$ \\
\hline Age $x$ SES & & $\begin{array}{c}-0.0046 \\
(0.0017)\end{array}$ & & $\begin{array}{c}-0.0093 \\
(0.0021)\end{array}$ \\
\hline \multicolumn{5}{|c|}{ Obesity Prevalence } \\
\hline Age & $\begin{array}{c}0.0059 \\
(0.0028)\end{array}$ & $\begin{array}{c}0.0059 \\
(0.0028)\end{array}$ & $\begin{array}{c}0.0060 \\
(0.0025)\end{array}$ & $\begin{array}{c}0.0059 \\
(0.0025)\end{array}$ \\
\hline SES & $\begin{array}{c}-0.0094 \\
(0.0018)\end{array}$ & $\begin{array}{c}-0.0093 \\
(0.0018)\end{array}$ & $\begin{array}{c}-0.0149 \\
(0.0022)\end{array}$ & $\begin{array}{c}-0.0148 \\
(0.0022)\end{array}$ \\
\hline Age $x$ SES & & $\begin{array}{c}-4.9 \mathrm{E}-4 \\
(1.5 \mathrm{E}-4)\end{array}$ & & $\begin{array}{c}-8.8 \mathrm{E}-4 \\
(1.6 \mathrm{E}-4)\end{array}$ \\
\hline
\end{tabular}

Note: See notes on Tables 1 and 3. Models correspond to those in columns (2a) and (2b) of Table 3. Sample sizes are 35,228 for males and 31,819 for females. 
Table 5: Predicted BMI and Obesity Prevalence by Age and SES

\begin{tabular}{ccccc}
\hline $\begin{array}{l}\text { Maternal Years } \\
\text { of Schooling }\end{array}$ & \multicolumn{2}{c}{ BMI } & \multicolumn{2}{c}{ Obesity Prevalence } \\
& 20 Years Old & 40 Years Old & 20 Years Old & 40 Years Old \\
\hline $\mathbf{9}$ & Full Sample & & & \\
$\mathbf{1 6}$ & 24.1 & 27.0 & $9.0 \%$ & $24.7 \%$ \\
& 23.3 & 25.1 & $6.0 \%$ & $12.1 \%$ \\
$\mathbf{9}$ & Males & & & \\
$\mathbf{1 6}$ & 24.9 & 27.6 & $10.2 \%$ & $24.7 \%$ \\
& 24.4 & 26.4 & $7.4 \%$ & $15.1 \%$ \\
$\mathbf{9}$ & Females & & & \\
$\mathbf{1 6}$ & 23.4 & 26.2 & $7.7 \%$ & $24.3 \%$ \\
\hline
\end{tabular}

Note: See notes on Tables 1 and 4. Predictions are obtained from models corresponding to (2a) and (2b) of Table 3. 
Table 6: Mechanisms and Correlates of SES and Age Gradients in BMI and Obesity Prevalence

\begin{tabular}{|c|c|c|c|c|c|c|c|c|c|c|}
\hline \multirow[b]{2}{*}{ Regressor } & \multicolumn{5}{|c|}{ Body Mass Index } & \multicolumn{5}{|c|}{ Obesity Prevalence } \\
\hline & (1) & (2) & (3) & (4) & (5) & (1) & (2) & (3) & (4) & (5) \\
\hline \multicolumn{11}{|c|}{ Full Sample } \\
\hline Age & $\begin{array}{c}0.1225 \\
(0.0286)\end{array}$ & $\begin{array}{c}0.1339 \\
(0.0285)\end{array}$ & $\begin{array}{c}0.1209 \\
(0.0288)\end{array}$ & $\begin{array}{c}0.1319 \\
(0.0286)\end{array}$ & $\begin{array}{c}0.1333 \\
(0.0290)\end{array}$ & $\begin{array}{c}0.0060 \\
(0.0019)\end{array}$ & $\begin{array}{c}0.0069 \\
(0.0019)\end{array}$ & $\begin{array}{c}0.0059 \\
(0.0019)\end{array}$ & $\begin{array}{c}0.0068 \\
(0.0019)\end{array}$ & $\begin{array}{c}0.0070 \\
(0.0020)\end{array}$ \\
\hline \multirow[t]{2}{*}{ SES } & $\begin{array}{l}-0.2017 \\
(0.0242)\end{array}$ & $\begin{array}{l}-0.1499 \\
(0.0256)\end{array}$ & $\begin{array}{c}-0.1686 \\
(0.0256)\end{array}$ & $\begin{array}{c}-0.1192 \\
(0.0273)\end{array}$ & $\begin{array}{c}-0.1117 \\
(0.0264)\end{array}$ & $\begin{array}{l}-0.0120 \\
(0.0015)\end{array}$ & $\begin{array}{c}-0.0077 \\
(0.0016)\end{array}$ & $\begin{array}{l}-0.0103 \\
(0.0016)\end{array}$ & $\begin{array}{c}-0.0060 \\
(0.0017)\end{array}$ & $\begin{array}{c}-0.0053 \\
(0.0016)\end{array}$ \\
\hline & Males & & & & & & & & & \\
\hline Age & $\begin{array}{c}0.1222 \\
(0.0396)\end{array}$ & $\begin{array}{c}0.1303 \\
(0.0392)\end{array}$ & $\begin{array}{c}0.1226 \\
(0.0396)\end{array}$ & $\begin{array}{c}0.1301 \\
(0.0393)\end{array}$ & $\begin{array}{c}0.1272 \\
(0.0400)\end{array}$ & $\begin{array}{c}0.0059 \\
(0.0028)\end{array}$ & $\begin{array}{c}0.0068 \\
(0.0029)\end{array}$ & $\begin{array}{c}0.0059 \\
(0.0029)\end{array}$ & $\begin{array}{c}0.0068 \\
(0.0029)\end{array}$ & $\begin{array}{c}0.0064 \\
(0.0030)\end{array}$ \\
\hline \multirow[t]{2}{*}{ SES } & $\begin{array}{l}-0.1215 \\
(0.0279)\end{array}$ & $\begin{array}{l}-0.0845 \\
(0.0319)\end{array}$ & $\begin{array}{c}-0.1048 \\
(0.0301)\end{array}$ & $\begin{array}{c}-0.0668 \\
(0.0328)\end{array}$ & $\begin{array}{c}-0.0616 \\
(0.0324)\end{array}$ & $\begin{array}{c}-0.0094 \\
(0.0018)\end{array}$ & $\begin{array}{c}-0.0050 \\
(0.0021)\end{array}$ & $\begin{array}{l}-0.0080 \\
(0.0020)\end{array}$ & $\begin{array}{l}-0.0036 \\
(0.0022)\end{array}$ & $\begin{array}{l}-0.0029 \\
(0.0021)\end{array}$ \\
\hline & Females & & & & & & & & & \\
\hline Age & $\begin{array}{c}0.1179 \\
(0.0415)\end{array}$ & $\begin{array}{c}0.1133 \\
(0.0418)\end{array}$ & $\begin{array}{c}0.1158 \\
(0.0415)\end{array}$ & $\begin{array}{c}0.1305 \\
(0.0418)\end{array}$ & $\begin{array}{c}0.1487 \\
(0.0425)\end{array}$ & $\begin{array}{c}0.0060 \\
(0.0025)\end{array}$ & $\begin{array}{c}0.0070 \\
(0.0025)\end{array}$ & $\begin{array}{c}0.0058 \\
(0.0025)\end{array}$ & $\begin{array}{c}0.0068 \\
(0.0025)\end{array}$ & $\begin{array}{c}0.0081 \\
(0.0025)\end{array}$ \\
\hline SES & $\begin{array}{l}-0.2877 \\
(0.0390)\end{array}$ & $\begin{array}{l}-0.2174 \\
(0.0423)\end{array}$ & $\begin{array}{c}-0.2344 \\
(0.0417)\end{array}$ & $\begin{array}{c}-0.1678 \\
(0.0457)\end{array}$ & $\begin{array}{c}-0.1529 \\
(0.0439)\end{array}$ & $\begin{array}{l}-0.0149 \\
(0.0022)\end{array}$ & $\begin{array}{c}-0.0105 \\
(0.0024)\end{array}$ & $\begin{array}{l}-0.0126 \\
(0.0024)\end{array}$ & $\begin{array}{c}-0.0084 \\
(0.0026)\end{array}$ & $\begin{array}{l}-0.0075 \\
(0.0025)\end{array}$ \\
\hline Education & No & Yes & No & Yes & Yes & No & Yes & No & Yes & Yes \\
\hline Race & No & No & Yes & Yes & Yes & No & No & Yes & Yes & Yes \\
\hline Other & No & No & No & No & Yes & No & No & No & No & Yes \\
\hline
\end{tabular}

Note: See notes on Tables 1 through 4. Regressions correspond to model (2a) of Table 3, with the inclusion of additional covariates detailed at the bottom of the table. Education indicates the highest grade completed by the respondent at the survey date. "Race" refers to dummy variables for (non-Hispanic) blacks and Hispanics. "Other" regressors include controls for family income, household composition (marital status and number of children), and health behaviors related to smoking, drinking, exercise, and job-related fitness and strength demands. See Table 1 and the text for additional details on these variables. 
Table 7: Decomposition of SES Gap in BMI and Obesity and 20 and 40 Years of Age

\begin{tabular}{|c|c|c|c|c|c|c|}
\hline \multirow[t]{2}{*}{ Explanatory Variables } & \multicolumn{2}{|c|}{ Full Sample } & \multicolumn{2}{|c|}{ Males } & \multicolumn{2}{|c|}{ Females } \\
\hline & $\mathrm{BMI}$ & Obesity & BMI & Obesity & BMI & Obesity \\
\hline \multicolumn{7}{|c|}{ 20-year olds } \\
\hline SES Gap & 0.825 & 0.0296 & 0.497 & 0.0275 & 1.258 & 0.0329 \\
\hline \multicolumn{7}{|l|}{ \% of Gap Explained by: } \\
\hline Education & $16.2 \%$ & $68.6 \%$ & $-8.8 \%$ & $76.1 \%$ & $26.9 \%$ & $61.4 \%$ \\
\hline Race & $12.9 \%$ & $12.6 \%$ & $9.6 \%$ & $12.4 \%$ & $16.5 \%$ & $16.1 \%$ \\
\hline Education and Race & $28.0 \%$ & $80.0 \%$ & $2.7 \%$ & $89.4 \%$ & $41.7 \%$ & $75.4 \%$ \\
\hline All Controls & $34.1 \%$ & $99.6 \%$ & $-5.8 \%$ & $92.7 \%$ & $57.6 \%$ & $111.9 \%$ \\
\hline \multicolumn{7}{|c|}{ 40-year olds } \\
\hline SES Gap & 1.862 & 0.1261 & 1.136 & 0.0962 & 2.563 & 0.1567 \\
\hline \multicolumn{7}{|l|}{ \% of Gap Explained by: } \\
\hline Education & $27.9 \%$ & $29.3 \%$ & $43.2 \%$ & $38.6 \%$ & $22.9 \%$ & $23.8 \%$ \\
\hline Race & $17.9 \%$ & $15.4 \%$ & $15.7 \%$ & $15.7 \%$ & $19.3 \%$ & $15.4 \%$ \\
\hline Education and Race & $44.6 \%$ & $43.6 \%$ & $59.4 \%$ & $54.5 \%$ & $41.0 \%$ & $38.0 \%$ \\
\hline All Controls & $47.5 \%$ & $46.5 \%$ & $68.4 \%$ & $62.5 \%$ & $42.6 \%$ & $39.1 \%$ \\
\hline
\end{tabular}

Note: The SES gap is the predicted difference for respondents whose mothers had 9 and 16 years of schooling respectively. These estimates are obtained from regressions corresponding to model (2b) in Table 3 . The percentages of the gap explained are obtained from models that add covariates for race and the respondent's level of schooling at the survey date, as specified, as well as interactions between (mean deviations of) these variables and age. The "all controls" models also include covariates for family income, household composition and health behaviors. 


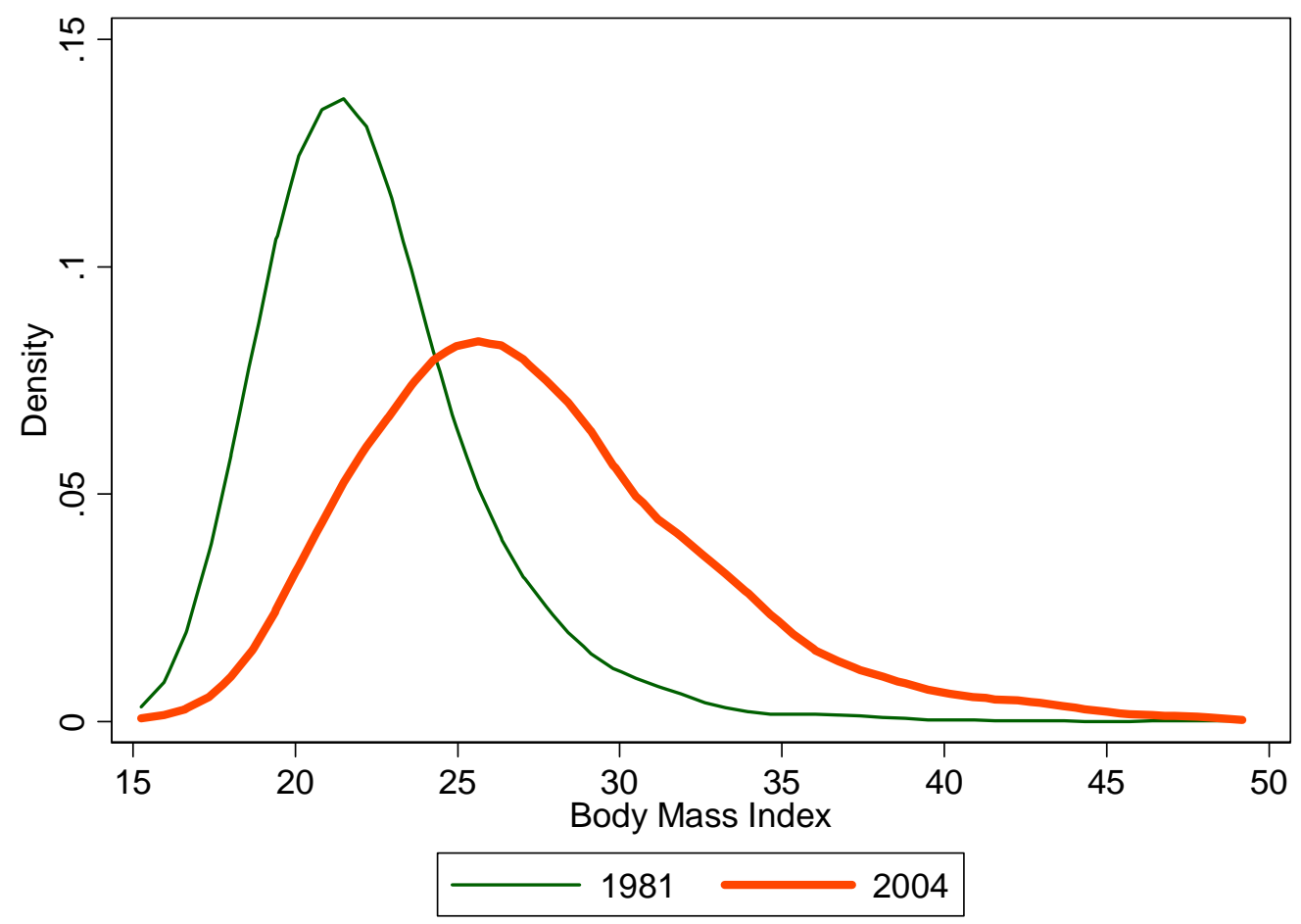

Figure 1: Body Mass Index in 1981 and 2004 

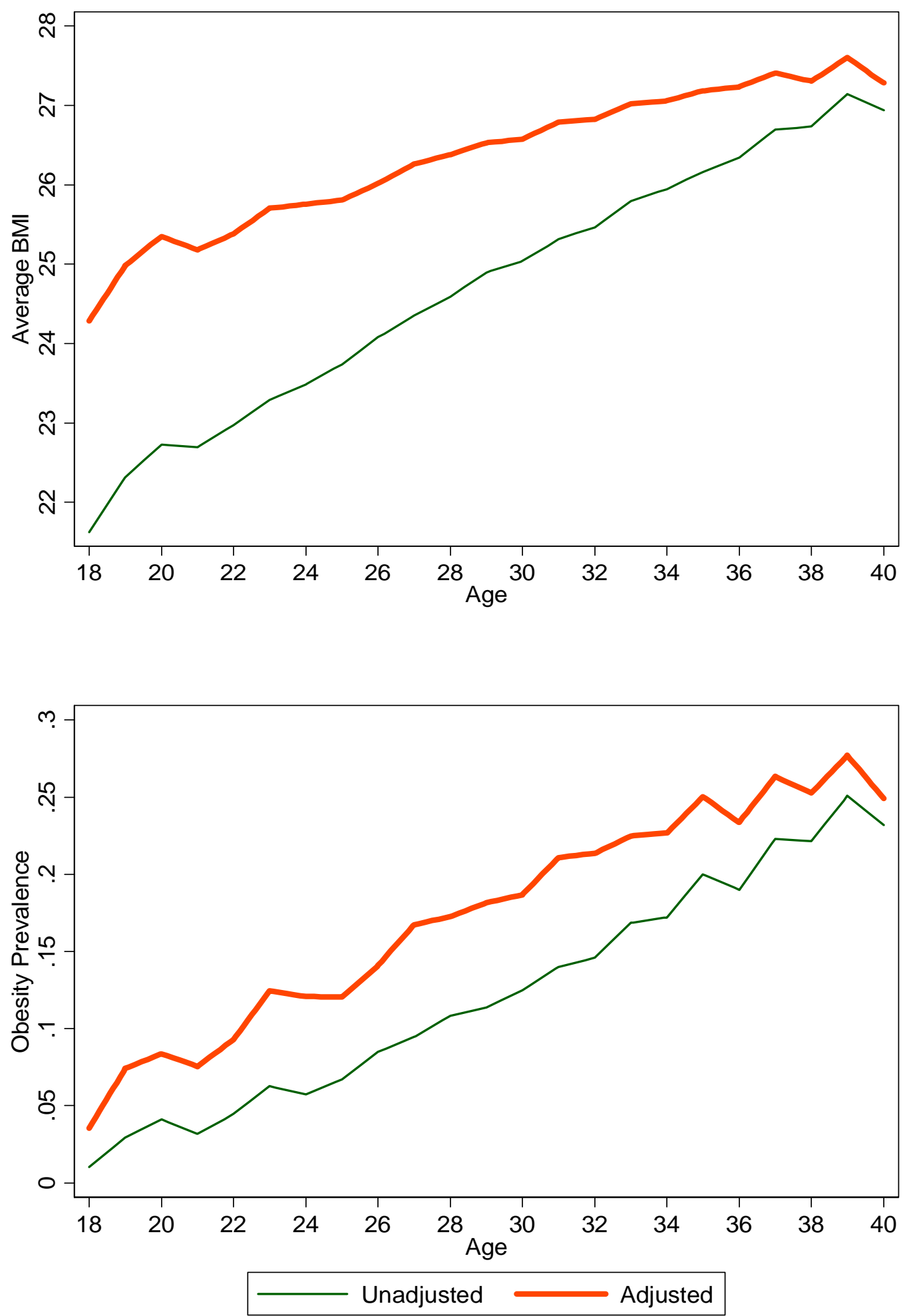

Figure 2: Average BMI and Obesity Prevalence by Age, With and Without Adjustment for Secular Trends 

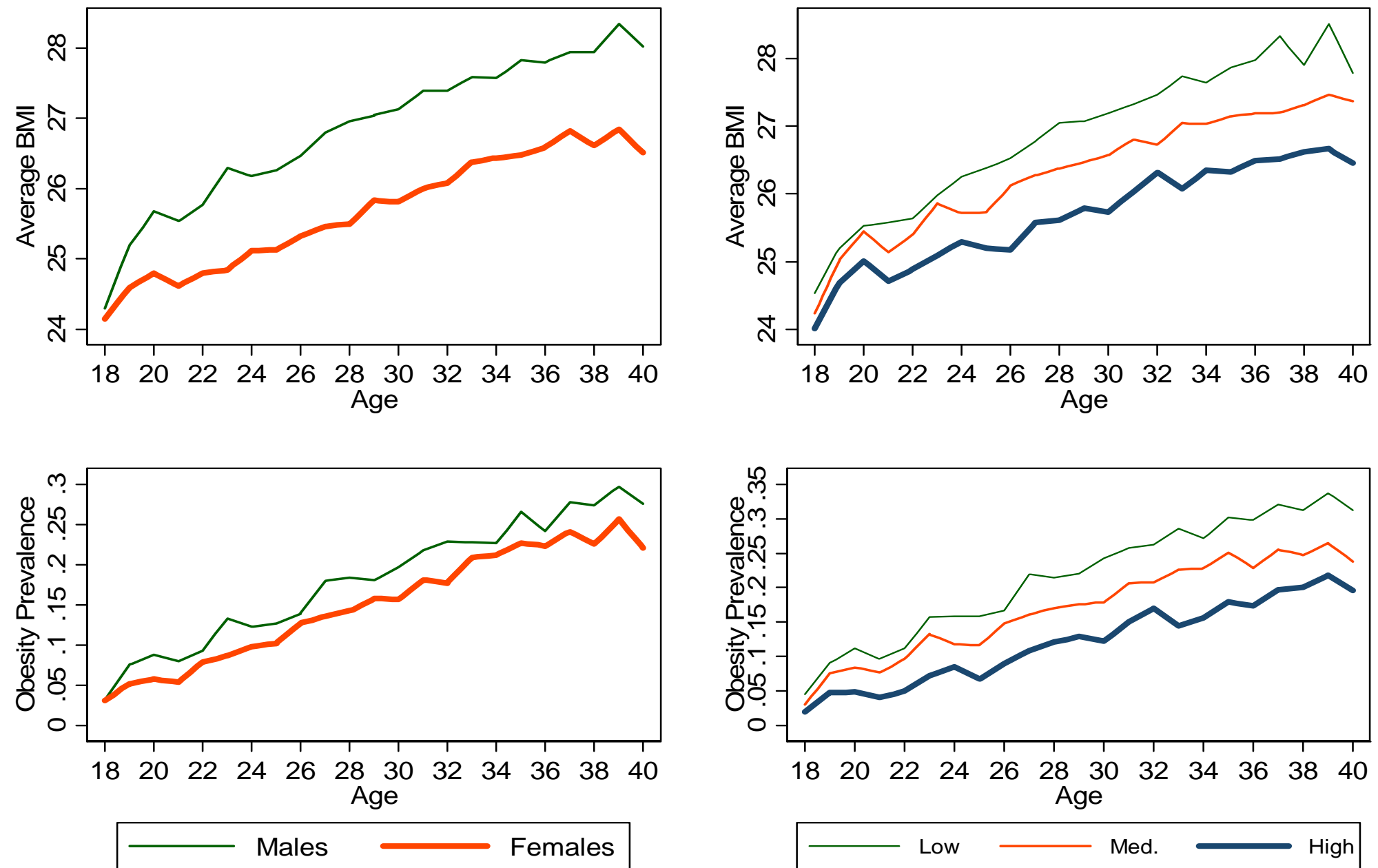

Figure 3: Age-Specific Average BMI and Obesity Prevalence By Gender and SES, Adjusted for Secular Trends 


\section{Appendix Tables}

Table A.1: Descriptive Statistics on BMI for Balanced and Unbalanced Samples

\begin{tabular}{ccccccc}
\hline & \multicolumn{3}{c}{ Balanced Panel } & \multicolumn{3}{c}{ Unbalanced Panel } \\
Year & Sample Size & Mean & $\begin{array}{c}\text { Standard } \\
\text { Error }\end{array}$ & Sample Size & Mean & $\begin{array}{c}\text { Standard } \\
\text { Error }\end{array}$ \\
\hline $\mathbf{1 9 8 1}$ & 4,628 & 22.344 & 0.065 & 8,578 & 22.508 & 0.056 \\
$\mathbf{1 9 8 2}$ & 4,582 & 22.604 & 0.069 & 8,452 & 22.769 & 0.057 \\
$\mathbf{1 9 8 5}$ & 4,545 & 23.401 & 0.079 & 8,180 & 23.558 & 0.067 \\
$\mathbf{1 9 8 6}$ & 4,580 & 23.797 & 0.086 & 7,899 & 23.951 & 0.067 \\
$\mathbf{1 9 8 8}$ & 4,564 & 24.340 & 0.088 & 7,714 & 24.537 & 0.072 \\
$\mathbf{1 9 8 9}$ & 4,590 & 24.493 & 0.086 & 7,819 & 24.691 & 0.073 \\
$\mathbf{1 9 9 0}$ & 4,609 & 24.865 & 0.084 & 7,713 & 25.068 & 0.073 \\
$\mathbf{1 9 9 2}$ & 4,667 & 25.328 & 0.094 & 7,748 & 25.585 & 0.082 \\
$\mathbf{1 9 9 3}$ & 4,708 & 25.532 & 0.092 & 7,783 & 25.738 & 0.080 \\
$\mathbf{1 9 9 4}$ & 4,767 & 25.754 & 0.091 & 7,752 & 25.969 & 0.081 \\
$\mathbf{1 9 9 6}$ & 4,823 & 26.240 & 0.095 & 7,622 & 26.395 & 0.084 \\
$\mathbf{1 9 9 8}$ & 4,878 & 26.657 & 0.098 & 7,428 & 26.761 & 0.088 \\
$\mathbf{2 0 0 0}$ & 4,949 & 27.009 & 0.100 & 7,226 & 27.219 & 0.089 \\
$\mathbf{2 0 0 2}$ & 4,996 & 27.289 & 0.099 & 7,059 & 27.515 & 0.098 \\
$\mathbf{2 0 0 4}$ & 5,022 & 27.387 & 0.100 & 7,062 & 27.679 & 0.094 \\
\hline
\end{tabular}

Note: Balanced sample excludes sample members with missing data on body weight during at least one survey year. The unbalanced sample includes these individuals. The size of the balanced sample varies over time because women are excluded in years they are pregnant or have recently given birth. 
Table A.2: Age-Specific Body Mass Index and Obesity Prevalence With and Without Adjustment for Secular Trends in Body Weight

\begin{tabular}{|c|c|c|c|c|c|c|c|}
\hline \multirow{3}{*}{ Age } & \multirow{3}{*}{$\begin{array}{c}\text { Full } \\
\text { Sample: } \\
\text { Not } \\
\text { Adjusted }\end{array}$} & \multicolumn{6}{|c|}{ Adjusted for Secular Trends in Body Weight } \\
\hline & & \multirow{2}{*}{$\begin{array}{c}\text { Full } \\
\text { Sample }\end{array}$} & \multicolumn{2}{|c|}{ Gender } & \multicolumn{3}{|c|}{ SES } \\
\hline & & & Males & Females & Low & Medium & High \\
\hline \multicolumn{8}{|c|}{ Body Mass Index } \\
\hline 20 & $\begin{array}{l}22.7 \\
(0.1)\end{array}$ & $\begin{array}{l}25.3 \\
(0.1)\end{array}$ & $\begin{array}{l}25.7 \\
(0.1)\end{array}$ & $\begin{array}{l}24.8 \\
(0.2)\end{array}$ & $\begin{array}{l}25.5 \\
(0.2)\end{array}$ & $\begin{array}{l}25.4 \\
(0.1)\end{array}$ & $\begin{array}{l}25.0 \\
(0.3)\end{array}$ \\
\hline 25 & $\begin{array}{l}23.7 \\
(0.1)\end{array}$ & $\begin{array}{l}25.8 \\
(0.1)\end{array}$ & $\begin{array}{l}26.3 \\
(0.1)\end{array}$ & $\begin{array}{l}25.1 \\
(0.1)\end{array}$ & $\begin{array}{l}26.4 \\
(0.2)\end{array}$ & $\begin{array}{l}25.7 \\
(0.2)\end{array}$ & $\begin{array}{l}25.2 \\
(0.2)\end{array}$ \\
\hline 30 & $\begin{array}{l}25.0 \\
(0.1)\end{array}$ & $\begin{array}{l}26.6 \\
(0.1)\end{array}$ & $\begin{array}{l}27.1 \\
(0.1)\end{array}$ & $\begin{array}{l}25.8 \\
(0.1)\end{array}$ & $\begin{array}{l}27.2 \\
(0.2)\end{array}$ & $\begin{array}{l}26.6 \\
(0.1)\end{array}$ & $\begin{array}{l}25.7 \\
(0.2)\end{array}$ \\
\hline 35 & $\begin{array}{l}26.2 \\
(0.1)\end{array}$ & $\begin{array}{l}27.2 \\
(0.1)\end{array}$ & $\begin{array}{l}27.8 \\
(0.1)\end{array}$ & $\begin{array}{l}26.5 \\
(0.2)\end{array}$ & $\begin{array}{l}27.9 \\
(0.2)\end{array}$ & $\begin{array}{l}27.1 \\
(0.2)\end{array}$ & $\begin{array}{l}26.3 \\
(0.3)\end{array}$ \\
\hline 40 & $\begin{array}{l}26.9 \\
(0.1)\end{array}$ & $\begin{array}{l}27.3 \\
(0.1)\end{array}$ & $\begin{array}{l}28.0 \\
(0.1)\end{array}$ & $\begin{array}{l}26.5 \\
(0.2)\end{array}$ & $\begin{array}{l}27.8 \\
(0.2)\end{array}$ & $\begin{array}{l}27.4 \\
(0.2)\end{array}$ & $\begin{array}{l}26.5 \\
(0.3)\end{array}$ \\
\hline \multicolumn{8}{|c|}{ Obesity Prevalence } \\
\hline 20 & $\begin{array}{c}4.1 \% \\
(0.6 \%)\end{array}$ & $\begin{array}{c}8.4 \% \\
(0.8 \%)\end{array}$ & $\begin{array}{c}8.8 \% \\
(1.1 \%)\end{array}$ & $\begin{array}{c}5.8 \% \\
(1.2 \%)\end{array}$ & $\begin{array}{l}11.1 \% \\
(1.7 \%)\end{array}$ & $\begin{array}{c}8.4 \% \\
(1.2 \%)\end{array}$ & $\begin{array}{c}4.9 \% \\
(1.6 \%)\end{array}$ \\
\hline 25 & $\begin{array}{c}6.7 \% \\
(0.7 \%)\end{array}$ & $\begin{array}{l}12.0 \% \\
(0.8 \%)\end{array}$ & $\begin{array}{l}12.7 \% \\
(1.2 \%)\end{array}$ & $\begin{array}{l}10.2 \% \\
(1.0 \%)\end{array}$ & $\begin{array}{l}15.8 \% \\
(1.4 \%)\end{array}$ & $\begin{array}{l}11.6 \% \\
(1.3 \%)\end{array}$ & $\begin{array}{c}6.7 \% \\
(1.4 \%)\end{array}$ \\
\hline 30 & $\begin{array}{l}12.5 \% \\
(0.7 \%)\end{array}$ & $\begin{array}{l}18.7 \% \\
(0.9 \%)\end{array}$ & $\begin{array}{l}19.7 \% \\
(1.3 \%)\end{array}$ & $\begin{array}{l}15.7 \% \\
(1.1 \%)\end{array}$ & $\begin{array}{l}24.2 \% \\
(1.7 \%)\end{array}$ & $\begin{array}{l}17.9 \% \\
(1.1 \%)\end{array}$ & $\begin{array}{l}12.2 \% \\
(1.6 \%)\end{array}$ \\
\hline 35 & $\begin{array}{l}20.0 \% \\
(0.9 \%)\end{array}$ & $\begin{array}{l}25.0 \% \\
(1.0 \%)\end{array}$ & $\begin{array}{l}26.6 \% \\
(1.5 \%)\end{array}$ & $\begin{array}{l}22.7 \% \\
(1.3 \%)\end{array}$ & $\begin{array}{l}30.2 \% \\
(1.8 \%)\end{array}$ & $\begin{array}{l}25.1 \% \\
(1.4 \%)\end{array}$ & $\begin{array}{l}17.9 \% \\
(2.2 \%)\end{array}$ \\
\hline 40 & $\begin{array}{l}23.2 \% \\
(1.0 \%)\end{array}$ & $\begin{array}{l}24.9 \% \\
(0.9 \%)\end{array}$ & $\begin{array}{l}27.5 \% \\
(1.5 \%)\end{array}$ & $\begin{array}{l}22.1 \% \\
(1.3 \%)\end{array}$ & $\begin{array}{l}31.3 \% \\
(1.8 \%)\end{array}$ & $\begin{array}{l}23.8 \% \\
(1.5 \%)\end{array}$ & $\begin{array}{l}19.6 \% \\
(2.2 \%)\end{array}$ \\
\hline
\end{tabular}

Note: See notes on Tables 1 and 2. Adjusted BMI and obesity is calculated by using data from the National Health and Nutrition Examination Surveys to remove the effects of secular trends. Details of the procedure are discussed in the text. Low, medium and high socioeconomic status refer to respondent's whose mothers completed $<12,12$ and $>12$ years of education. 
Table A.3: Additional Econometric Estimates of Mechanisms and Correlates of SES and Age Gradients

\begin{tabular}{|c|c|c|c|c|c|c|c|}
\hline Regressor & (1) & (2) & (3) & (4) & (5) & (6) & (7) \\
\hline \multicolumn{8}{|c|}{ Body Mass Index } \\
\hline Age & $\begin{array}{c}0.1225 \\
(0.0286)\end{array}$ & $\begin{array}{c}0.1339 \\
(0.0285)\end{array}$ & $\begin{array}{c}0.1209 \\
(0.0288)\end{array}$ & $\begin{array}{c}0.1319 \\
(0.0286)\end{array}$ & $\begin{array}{c}0.1253 \\
(0.0285)\end{array}$ & $\begin{array}{c}0.1167 \\
(0.0295)\end{array}$ & $\begin{array}{c}0.1354 \\
(0.0289)\end{array}$ \\
\hline SES & $\begin{array}{l}-0.2017 \\
(0.0242)\end{array}$ & $\begin{array}{c}-0.1499 \\
(0.0256)\end{array}$ & $\begin{array}{c}-0.1686 \\
(0.0256)\end{array}$ & $\begin{array}{c}-0.1192 \\
(0.0273)\end{array}$ & $\begin{array}{c}-0.1936 \\
(0.0241)\end{array}$ & $\begin{array}{l}-0.2005 \\
(0.0245)\end{array}$ & $\begin{array}{l}-0.1130 \\
(0.0263)\end{array}$ \\
\hline Education & & $\begin{array}{c}-0.1464 \\
(0.0343)\end{array}$ & & $\begin{array}{c}-0.1390 \\
(0.0340)\end{array}$ & & & $\begin{array}{l}-0.1783 \\
(0.0356)\end{array}$ \\
\hline Hispanic & & & $\begin{array}{c}0.6422 \\
(0.1853)\end{array}$ & $\begin{array}{c}0.6818 \\
(0.1837)\end{array}$ & & & $\begin{array}{c}0.6149 \\
(0.1839)\end{array}$ \\
\hline Black & & & $\begin{array}{c}1.1463 \\
(0.1488)\end{array}$ & $\begin{array}{c}1.0995 \\
(0.1480)\end{array}$ & & & $\begin{array}{c}1.1762 \\
(0.1523)\end{array}$ \\
\hline Income & & & & & $\begin{array}{l}-.0017 \\
(.0004)\end{array}$ & & $\begin{array}{l}-.0012 \\
(.0004)\end{array}$ \\
\hline \multicolumn{8}{|c|}{ Obesity Prevalence } \\
\hline Age & $\begin{array}{c}0.0060 \\
(0.0019)\end{array}$ & $\begin{array}{c}0.0069 \\
(0.0019)\end{array}$ & $\begin{array}{c}0.0059 \\
(0.0019)\end{array}$ & $\begin{array}{c}0.0068 \\
(0.0019)\end{array}$ & $\begin{array}{c}0.0061 \\
(0.0019)\end{array}$ & $\begin{array}{c}0.0057 \\
(0.0020)\end{array}$ & $\begin{array}{c}0.0071 \\
(0.0020)\end{array}$ \\
\hline SES & $\begin{array}{c}-0.0120 \\
(0.0015)\end{array}$ & $\begin{array}{l}-0.0077 \\
(0.0016)\end{array}$ & $\begin{array}{c}-0.0103 \\
(0.0016)\end{array}$ & $\begin{array}{c}-0.0060 \\
(0.0017)\end{array}$ & $\begin{array}{l}-0.0114 \\
(0.0015)\end{array}$ & $\begin{array}{l}-0.0115 \\
(0.0014)\end{array}$ & $\begin{array}{l}-0.0054 \\
(0.0017)\end{array}$ \\
\hline Education & & $\begin{array}{c}-0.123 \\
(0.0022)\end{array}$ & & $\begin{array}{c}-0.119 \\
(0.0022)\end{array}$ & & & $\begin{array}{c}-0.139 \\
(0.0024)\end{array}$ \\
\hline Hispanic & & & $\begin{array}{c}0.0317 \\
(0.0127)\end{array}$ & $\begin{array}{c}0.0351 \\
(0.0125)\end{array}$ & & & $\begin{array}{c}0.0316 \\
(0.0124)\end{array}$ \\
\hline Black & & & $\begin{array}{c}0.0657 \\
(0.0102)\end{array}$ & $\begin{array}{c}0.0617 \\
(0.0102)\end{array}$ & & & $\begin{array}{c}0.0617 \\
(0.0106)\end{array}$ \\
\hline Income & & & & & $\begin{array}{l}-1.3 \mathrm{E}-4 \\
(2.1 \mathrm{E}-5)\end{array}$ & & $\begin{array}{l}-8.1 \mathrm{E}-5 \\
(1.9 \mathrm{E}-5)\end{array}$ \\
\hline $\begin{array}{l}\text { Additional } \\
\text { Controls }\end{array}$ & No & No & No & No & No & Yes & Yes \\
\hline
\end{tabular}

Note: See notes on Table 6. Additional controls here refer to health behaviors and household composition. These estimates are for a combined sample of men and women. 